\title{
Spillover Phenomena and Its Striking Impacts in Electrocatalysis for Hydrogen and Oxygen Electrode Reactions
}

\author{
Georgios D. Papakonstantinou, ${ }^{1}$ Jelena M. Jaksic, ${ }^{1}$ Diamantoula Labou, ${ }^{1}$ \\ Angeliki Siokou, ${ }^{1}$ and Milan M. Jaksic ${ }^{1,2}$ \\ ${ }^{1}$ Institute of Chemical Engineering and High Temperature Chemical Processes, FORTH, 26500 Patras, Greece
${ }^{2}$ Faculty of Agriculture, University of Belgrade, 11080 Belgrade, Serbia
}

Correspondence should be addressed to Milan M. Jaksic, milan@iceht.forth.gr

Received 8 May 2011; Accepted 5 September 2011

Academic Editor: Gianluigi Botton

Copyright ( 2011 Georgios D. Papakonstantinou et al. This is an open access article distributed under the Creative Commons Attribution License, which permits unrestricted use, distribution, and reproduction in any medium, provided the original work is properly cited.

\begin{abstract}
The core subject of the present paper represents the interrelated spillover (effusion) phenomena both of the primary oxide and the $\mathrm{H}$-adatoms, their theory and practice, causes, appearances and consequences, and evidences of existence, their specific properties, and their alterpolar equilibria and kinetic behavior, structural, and resulting catalytic, and double layer charging features. The aim is to introduce electron conductive and $\mathrm{d}-\mathrm{d}$ interactive individual and composite (mixed valence) hypo-doxide compounds, of increased altervalent capacity, or their suboxides (Magnéli phases), as the interactive catalytic supports and therefrom provide (i) the strong metal-support interaction (SMSI) catalytic effect and (ii) dynamic spillover interactive transfer of primary oxides $(\mathrm{M}-\mathrm{OH})$ and free effusional $\mathrm{H}$-adatoms for further electrode reactions and thereby advance the overall electrocatalytic activity. Since hypo-d-oxides feature the exchange membrane properties, the higher the altervalent capacity, the higher the spillover effect. In fact, altervalent hypo-d-oxides impose spontaneous dissociative adsorption of water molecules and then spontaneously pronounced membrane spillover transferring properties instantaneously resulting with corresponding bronze type $\left(\mathrm{Pt} / \mathrm{H}_{x} \mathrm{WO}_{3}\right)$ under cathodic and/or its hydrated state $\left(\mathrm{Pt} / \mathrm{W}(\mathrm{OH})_{6}\right)$, responsible for $\mathrm{Pt}-\mathrm{OH}$ effusion, under anodic polarization, this way establishing instantaneous reversibly revertible alterpolar bronze features $\left(\mathrm{Pt} / \mathrm{H}_{0.35} \mathrm{WO} \mathrm{O}_{3} \Leftrightarrow \mathrm{Pt} / \mathrm{W}(\mathrm{OH})_{6}\right)$ and substantially advanced electrocatalytic properties of these composite interactive electrocatalysts. Such nanostructured-type electrocatalysts, even of mixed-valence hypo-d-oxide structures $\left(\mathrm{Pt} / \mathrm{H}_{0.35} \mathrm{WO}_{3} / \mathrm{TiO}_{2} / \mathrm{C}, \mathrm{Pt} / \mathrm{H}_{x} \mathrm{NbO}_{3} / \mathrm{TiO}_{2} / \mathrm{C}\right)$, have for the first time been synthesized by the sol-gel methods and shown rather high stability, electron conductivity, and nonexchanged initial pure monobronze spillover and catalytic properties. Such a unique electrocatalytic system, as the striking target issue of the present paper, has been shown to be the superior for substantiation of the revertible cell assembly for spontaneous reversible alterpolar interchanges between PEMFC and WE. The main target of the present thorough review study has been to throw some specific insight light on the overall spillover phenomena and their effects in electrocatalysis of oxygen and hydrogen electrode reactions from diverse angles of view and broad contemporary experimental methods and approaches (XPS, FTIR, DRIFT, XRD, potentiodynamic spectra, UHRTEM).
\end{abstract}

\section{Introduction}

1.1. Spillover Phenomena: Their Causes, Properties, Consequences, and Uses. Spillover phenomena impose advanced electrocatalytic effects on and play significant kinetic enhancement role in various electrochemical processes, in particular for the oxygen and hydrogen electrode reactions [1-4]. Namely, the fundamental Guldberg-Waage law of mass action (1865-1879) [5,6] predicts that the faster the spillover (or effusion) effect of the reacting intermediate species in the RDS (Rate Determining Step), the faster the corresponding electrode reaction becomes.

The first spillover phenomenon in heterogeneous catalysis was observed and defined by Boudart et al. [7, 8] for the interactive supported bronze-type $\left(\mathrm{Pt} / \mathrm{WO}_{3}\right)$ catalyst, initially at high temperature (above $400^{\circ} \mathrm{C}$ ) for pure solid system. Meanwhile, after the dissociative adsorption of water molecules on hypo-d-oxide support of $\mathrm{Pt}$, the 
fast interactive effusion of $\mathrm{H}$-adatoms over its hydrated $\left(\mathrm{W}(\mathrm{OH})_{6}\right)$ surface becomes dramatically sped up even at ambient conditions in the ultimate presence of condensed at least monolayered aqueous precipitate $[9,10]$. This is significant both for the evidence of the extremely fast spillover widespreading migration and thereby resulting with imposed the reversible substrate reduction. The latter finally leads to the corresponding form of electrocatalytically active bronze $\left(\mathrm{Pt} / \mathrm{H}_{0.35} \mathrm{WO}_{3}\right)$ for cathodic processes, in which nonstoichiometric incorporated hydrogen obeys the same free reactive properties like adsorptive $\mathrm{H}$-adatoms $(\mathrm{Pt}-\mathrm{H})$ and is the main source for the electrode or heterogeneous catalytic reaction. In other words, the point is that spontaneous dissociative adsorption of water molecules imposes much smaller activation energy for transformation of the resulting hydrated $\mathrm{W}(\mathrm{OH})_{6}$ into corresponding bronze state $\left(\mathrm{Pt} / \mathrm{H}_{0.35} \mathrm{WO}_{3}\right)$, even at ambient temperature, than the initial oxide $\mathrm{WO}_{3}$ and, thereby, dramatically facilitated the overall spillover effect under pronounced wet status.

As the present study is of the same significance to notice and discuss the dissociative hydrogen adsorption followed by fast spillover, establishing in this way the storage capacity of $\mathrm{H}$-adatoms on the wet sol-gel developed surface of carbon current collecting electrocatalysts support (like E-tek Vulcan XC-72), in particular, facilitated by the metallic part of catalyst [11-14] and the hydrated hypo-d-oxide support. $A b$ initio molecular orbital studies have shown that adsorption of $\mathrm{H}$-adatoms on the graphite basal plane [12] is an exothermic process. As the consequence, hydrogen spillover implies the transfer of electrons to acceptors within the support, this way modifying the chemical nature of the latter, activating previously inactive substrate, and inducing $\mathrm{H}$ adatoms spillover sorption like laterally widespread expanding mobile repulsive dipoles [11]. In such a way oxygen functional groups usually facilitate $\mathrm{H}$-adatoms spillover and their reductive interaction (rough value $1,200 \mathrm{~mol} / \mathrm{cm}^{2} / \mathrm{s}$, with linear velocities of $100 \mathrm{~cm} / \mathrm{s}$ at edges of Pt crystallites, reducing down to a still high value of $5 \mathrm{~cm} / \mathrm{s}$ midway between Pt particles or for about eight to even nine orders of magnitude amounting the transferring distance relative to the radius of spillover dispersing species), so that formation of Mo-bronze is an even faster process relative to tungsten [12]. The fascinating fact is that such spillover transferring rates are obtained within mild $\mathrm{pH}$ conditions and even upon mild hydroxide species, far from concentrated phosphoric acid of contemporary PEMs for actual and prospective fuel cells.

The first decisive step towards rather fast spillover expanding phenomena of the primary oxide $(\mathrm{M}-\mathrm{OH})$ has been the consequence of a strong first principle thermodynamic confirmed evidence (density functional calculations, DFC) [15] that water molecules undergo prevailing (for more than 50 percent of the entire available surface) spontaneous dissociative adsorption on anatase and even rutile titania and more so on the higher altervalent oxides [16] of tungsten, tantalum, and/or niobium (Figure 1). In addition, the first-principles molecular-dynamic simulations showed the existence of a mechanism for thermodynamically favored spontaneous dissociation of water molecules even at low coverage of oxygen vacancies of the anatase (101) surface and consequently to the Magneli phases $\left(\mathrm{Ti}_{n} \mathrm{O}_{(2 n-1)}\right.$, in average $\mathrm{Ti}_{4} \mathrm{O}_{7}$ ), as substantially suboxide structure significant both as highly bulk electronic conductive $[2,3]$, membrane-type surface transferring hydroxide species and interactive catalyst support [17-19]. In fact, this is the status of reversible opencircuit dissociative adsorption of water molecules at the equilibrium state. Meanwhile, in the presence of the nanosized metallic part of the catalyst and continuous enough moisture supply, directional electric field (or electrode polarization) further disturbs such an established equilibria and dynamically imposes further continuous forced dissociation of water molecules, and, as the consequence, their membrane transport properties [17-19] and the resulting spillover features $[1-4,20,21]$. Heterogeneous catalysis broadly employs the Tauster [22-25] SMSI (strong metal-support interaction) effect to increase the overall catalytic activity, but so far the additional interactive spillover contribution of the primary oxide $(\mathrm{M}-\mathrm{OH})$, in particular for the catalytic oxidation processes, has not been noticed.

In such a context, the catalytic water-gas shift (WGS) reaction $\left(\mathrm{H}_{2} \mathrm{O}+\mathrm{CO} \Rightarrow \mathrm{H}_{2}+\mathrm{CO}_{2}\right)$ has two or even three orders of magnitude higher reaction rate on the same metal catalyst interactive (SMSI) supported on hypo-d- than upon sp-oxides $[26,27]$ and, by the electrochemical promotion, (EPOC) has already been predestined for further catalytic advances and the efficient separation of final products [28].

In the same respect, Daté and Haruta [29] has pointed out that advanced $\mathrm{Au} / \mathrm{TiO}_{2}$ interactive supported heterogeneous catalysts feature their pronouncedly high activity for direct $\mathrm{CO}$ oxidation only when provided with the moisture in the gas stream above some critical content. In fact every SMSI catalytic process, based on the interactive supported hypo-d-oxides and the resulting spillover of the primary oxide, a priori implies some decisive threshold in continuous moisture supply below which there is no oxidation of reacting species.

In the same sense Völkening et al. [30] have in addition shown and experimentally proved by HREEL spectra along with STM images that the Doebereiner catalytic reaction of hydrogen oxidation upon Pt surface, even at low temperatures $(140 \mathrm{~K})$, proceeds with remarkable amounts of the primary oxide $\left(\mathrm{OH}_{\mathrm{ads}}\right)$, as the decisive and accumulated intermediate, including the auto- or self-catalytic step with adsorbed water molecules:

$$
\mathrm{O}_{\text {ads }}+\mathrm{H}_{2} \mathrm{O}_{\text {ads }} \Longrightarrow 2 \mathrm{OH}_{\text {ads }} \text {. }
$$

In fact, Ertl has pointed out the substantial autocatalytic role and the significance of water molecules in heterogeneous catalysis for oxidation processes that in general proceed over the primary oxide generation. The present study in the same sense reveals the increase of the overall reversible reaction rate of the primary oxide generation:

$$
\mathrm{M}+2 \mathrm{H}_{2} \mathrm{O} \Leftrightarrow \mathrm{M}-\mathrm{OH}+\mathrm{H}_{3} \mathrm{O}^{+}+\mathrm{e}^{-},
$$

and its further undisturbed spillover both caused by the pronounced and the decisive effect of polarized water dipoles within the double layer [31]. Namely, the latter (2) represents 


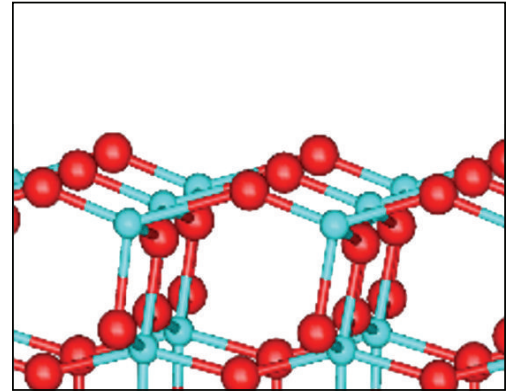

(a)

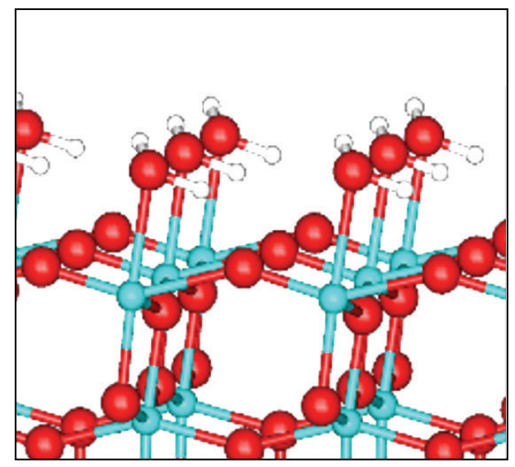

(c)

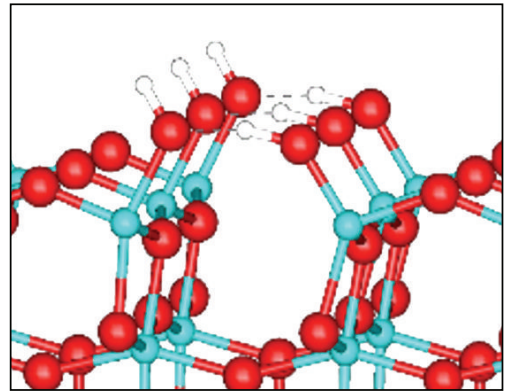

(b)

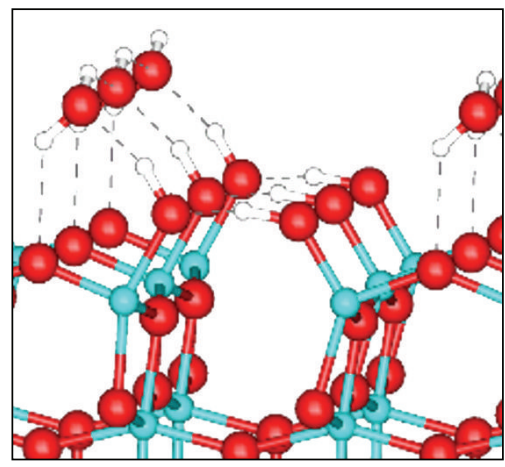

(d)

FIGURE 1: The perspective views of DFT-optimized atomic structures for (a) the clean anatase (ADM) ad-molecule model of unreconstructed (001) surface, (b) the dissociated state of water ( 0.5 monolayer) on (001), (c) the relaxed geometries of molecular state of adsorbed water (1.0 monolayer of hydroxylated anatase) on (001), and (d) the mixed state of water on (001) with a half-dissociated coverage of adsorbed monolayer water molecules (courtesy by Vittadini cf. [15]).

the electrochemical and electrocatalytic equivalent to the Ertl mechanism (1) in heterogeneous catalysis. In fact, it is well known in the electrochemical science from cyclic voltammograms scanned on Pt and Au [32-37] that the anodic adsorptive primary oxide growth and its cathodic desorption proceed as highly reversible and thereby extremely fast electrode processes. In principle, such typical dipoles (M$\mathrm{OH}$ ) are $1: 1$ employed within the broader potential range for the double layer capacitor charging and discharging $[1,4]$, and this is proved by the corresponding symmetric and highly reversible potentiodynamic peaks. What otherwise would dipoles do within double layer except to change the surface potential of an electrode and correspondingly the entire work function $[1-4,20,21]$ ? Since the heterogeneous reaction of formaldehyde oxidation with $\mathrm{Pt}-\mathrm{OH}$, and in particular $\mathrm{Au}-\mathrm{OH}$, proceeds as a fast reversible reaction mass transfer limited, and, since $\mathrm{HCHO}$ is soluble in all ratios in aqueous media, to prove almost unlimited the primary oxide generation rate cyclic voltammograms have been scanned within the broader concentration range of the latter $[4,38]$. Namely, it has then been clearly shown that for the one order of magnitude higher $\mathrm{HCHO}$ content correspondingly increased limiting current values of its anodic oxidation, or the corresponding peak values in the present cyclic voltammogram spectra (Figures 2 (a) and 2(b)) $[1,4,20,21$, 38]. Such a fast heterogeneous reaction of anodic $\mathrm{HCHO}$ oxidation is apparently able to postpone within an unusually large potential range the recombination of the primary (Pt$\mathrm{OH})$ into the more polarizable, more adsorptive, and more stable surface oxide $(\mathrm{Pt}=\mathrm{O})$.

1.2. Specific Dipole Properties and Spillover Causes of the Primary Oxide. The reversible fast-reacting primary oxide $(\mathrm{M}-\mathrm{OH})$ arises monolayer adsorbed and distinctly marked by a specific potentiodynamic peak, as the first step of water oxidation ((1) and (2)), immediately after the double layer charging range of many metals, first of all on $\mathrm{Ru}, \mathrm{Au}, \mathrm{Pt}, \mathrm{Rh}$, $\mathrm{Ag}$ [32-37]. Due to its chemically unstable reactive properties and consequently so fast decomposition recombination, leading to the irreversible and stable surface oxide $(\mathrm{M}=\mathrm{O})$ formation, the corresponding reversible peak usually extends in mineral acids and alkaline solutions within a narrow potential range, except when interactively supported on hypo-d-oxides and the latter being continuously supplied by water moisture. Similar behavior is a feature of some other transition metal primary-type oxides of common formulas and structure, like $\mathrm{MoO}(\mathrm{OH}), \mathrm{NiOOH}$, and $\mathrm{WO}_{2}(\mathrm{OH})$, and can be identified by corresponding peaks within their potentiodynamic and XPS spectra $[39,40]$. The point is that all transition metals of any, or in particular high, altervalent capacity, afford the reversible primary-oxide-type states, usually of pronounced catalytic activity and high electronic conductive properties $\left(\mathrm{WO}(\mathrm{OH}), \mathrm{MoO}_{2}(\mathrm{OH}), \mathrm{Pt}-\mathrm{OH}, \mathrm{Au}-\right.$ $\mathrm{OH})$, but unfortunately, in their oxidation, sequences end up 


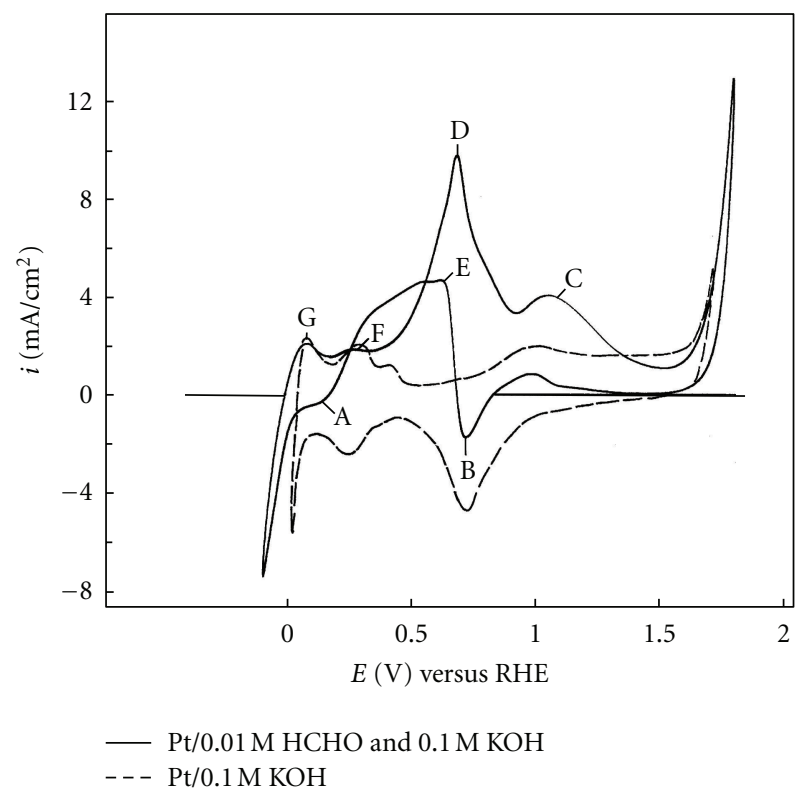

(a)

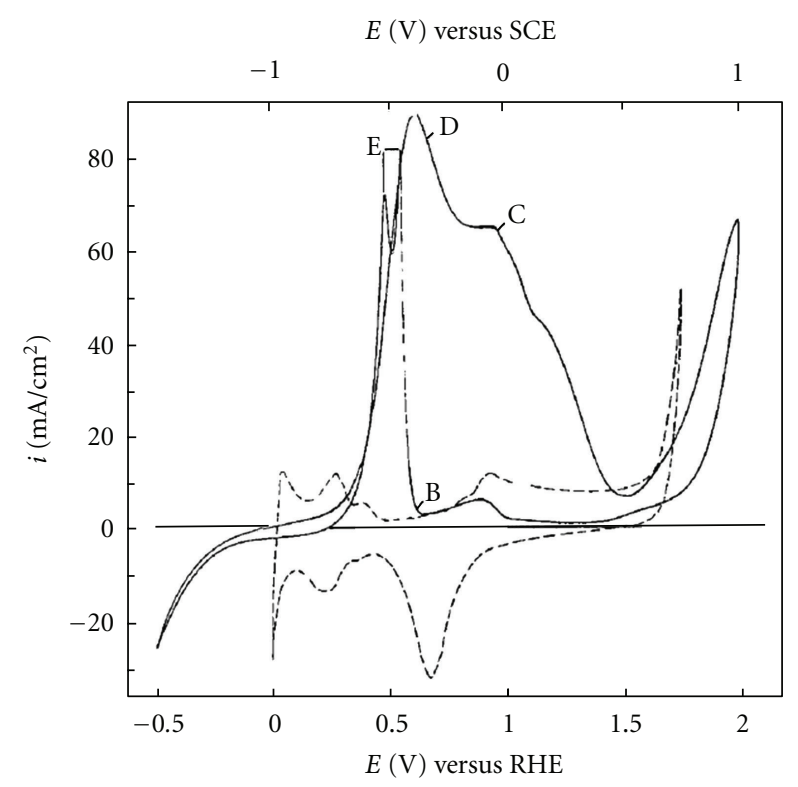

$\mathrm{Pt} / 0.1 \mathrm{M} \mathrm{HCHO}$ and $0.1 \mathrm{M} \mathrm{KOH}$

(b)

FIgUre 2: Cyclic voltammograms scanned on a polycrystalline Pt wire electrode in alkaline $(0.1 \mathrm{M} \mathrm{KOH}$, dashed lines) solution and in admixture of formaldehyde $\left(0.01 \mathrm{M}(\mathrm{a})\right.$ and $0.1 \mathrm{M} \mathrm{HCHO} \mathrm{(b),} \mathrm{full} \mathrm{lines)} \mathrm{at} 200 \mathrm{mV} \cdot \mathrm{s}^{-1}$ sweep rate between hydrogen and oxygen potential evolving limits. Labels: (A) reversible hydrogen adsorption peak; (B) irreversible Pt surface oxide ( $\mathrm{Pt}=\mathrm{O})$ desorption peak; (C, D) successive peaks of anodic aldehyde oxidation; (E) sudden sharp current jump and reverse peak of repeated HCHO oxidation; (G, F) reversible Hadatoms oxidation and desorption peaks [38].

with nonconductive and catalytically inactive higher valence oxide states $\left(\mathrm{MoO}_{3}, \mathrm{WO}_{3}, \mathrm{Pt}=\mathrm{O}, \mathrm{Au}=\mathrm{O}, \mathrm{NiO}_{2}\right)$; otherwise the whole aqueous electrochemistry would feature another and quite different physiognomy!

The primary oxide species have dipole properties with prevailing ionic character of the majority of charge being transferred to the metal catalyst (Scheme 1) and thus appear weakly adsorbed at the interface $[31,41]$. Such a state of the adsorptive binding strength varies from the less to the catalytically more active transition metals, from the lower towards the higher d-band electronic filling (density), or from the stronger to the weaker adsorptive bonds decisive for the RDS and substantially defines the overall electrocatalytic activity for both the HOR and ORR. This is the core difference between the reversible and fast-reacting primary oxide relative to the highly polarizable surface oxide, whose polarization difference amounts for more than $600 \mathrm{mV}$. Meanwhile, this is the reason of a coincidence that reversibly adsorbed $\mathrm{H}$-adatoms and primary oxides feature almost the same enthalpies of adsorptive bonding upon catalytically active transition metal electrode substrates [31, 41].

Although their existence is clearly indicated by XP spectra [39, 40], under electrode polarization primary oxides feature some unique specific fluent (jellium [42] or fluid) structure of dipoles with noticeable Pauli's repulsion (the spillover precondition) amongst adjacent $\mathrm{M}-\mathrm{OH}$ species (Scheme 1). The latter causes their rearrangement into an antiparallel structure $\mathrm{OH}$-adsorbate being oriented in the upright position, with the $\mathrm{O}$-atoms closest to the metal plane [31]), and, consequently, there is no surface change monitoring in the course of the in situ STM scans, as might be expected along with the corresponding charge transfer for their adsorptive generation within the reversible potentiodynamic peak [41]. In fact, their double-layer charging package imposes such a jellium fluent properties in distinction to the primary oxide free distribution upon simple heterogeneous catalyst surfaces [30]. The $\mathrm{M}-\mathrm{OH}$ adsorbates are attracted towards and prefer the high coordination three-fold hollow sites on all transition elements, the adsorption energy for hollow and on-top sites being comparable for all d metals, and; consequently, they donate some electric charge to the surface to establish a dipole state (Scheme 1), in particular when a positive polarization field is imposed, as a substantially distinct example to the nonpolarizable Ertl et al. issue [30] in heterogeneous catalysis. The trends in the bonding of the primary oxide (M-OH, or the "hydroxyl species" [43]) have been similar in their nature to the surface oxide $(\mathrm{M}=\mathrm{O})$, with the difference that the weaker covalent interaction with the $\mathrm{d}$ states is due to the lower degeneracy of the $\mathrm{OH}^{*}$ species $1 \pi$ level in comparison with 2 p level of $\mathrm{M}=\mathrm{O}$ and, in addition, the presence of the hydrogen atom, which pools the whole $\mathrm{OH}$-species away from the surface (as confirmed by dipole moment measurements) [31]. Such typical dipole repulsive features stay in the core of the spillover properties of primary oxides. On the contrary, the $\mathrm{H}$-adatoms form a covalent adsorptive bond with transition metals, and, thereby, the effect of exerted electric field upon had a smaller impact. The Pauli repulsion becomes predominant due to the 


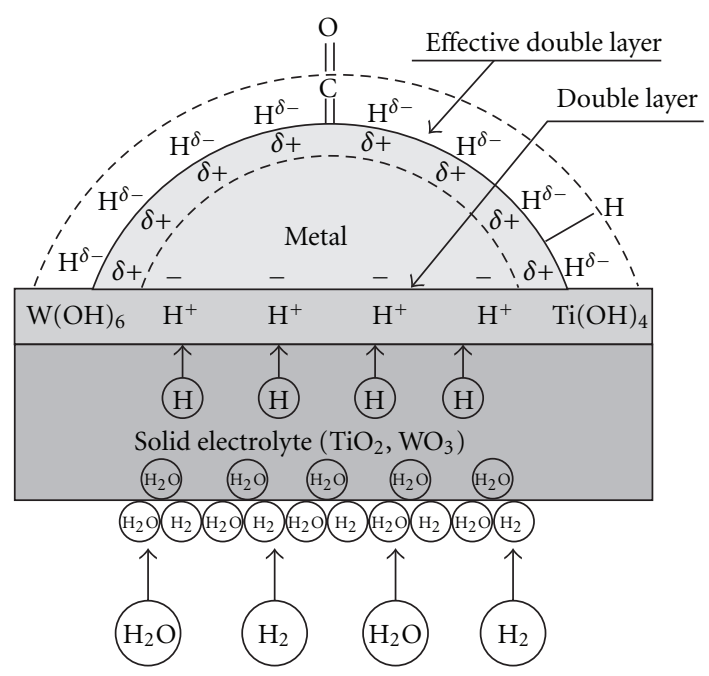

(a)

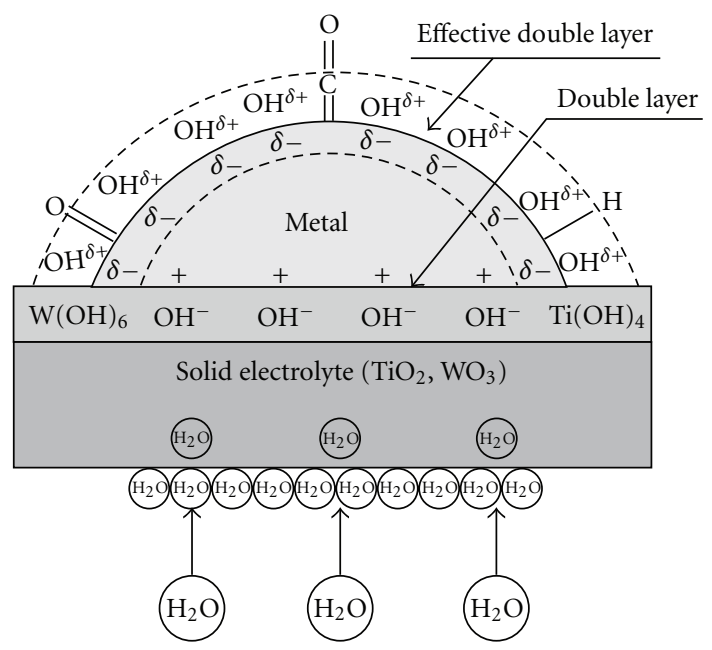

(b)

Scheme 1: Model presentation for the SMSI effect, resulting in the spillover transfer of $\mathrm{H}$-adatoms within the bronze nanostructure $\left(\mathrm{Pt} / \mathrm{H}_{0.35} \mathrm{WO}_{3}\right.$, (a)) and/or the primary oxide $(\mathrm{M}-\mathrm{OH})$ effusion, as a dipole along the hydrated counterpart $\left(\mathrm{Pt} / \mathrm{W}(\mathrm{OH})_{6},(\mathrm{~b})\right)$, further continuously transferring them upon the metallic part $(\mathrm{Pt})$ of catalyst, otherwise both originating from the hypo-doxide continuously fed by moisture stream to such a composite $\left(\mathrm{M} / \mathrm{TiO}_{2}, \mathrm{WO}_{3}\right)$ electrocatalyst structure and maintaining them in the reversible interchangeable equilibrium $\left(\mathrm{Pt} / \mathrm{H}_{0.35} \mathrm{WO}_{3} \Leftrightarrow\right.$ $\left.\mathrm{Pt} / \mathrm{W}(\mathrm{OH})_{6}\right)$ (constructed by Dimitris Tsiplakides).

increased electron density on the primary oxide adsorptive state with open-shell electronic configuration. The difference in adsorptive bonding upon different $\mathrm{d}$ metals is primarily explained by diversities in interaction with the d-band states, since transition metals are characterized by a broad $\mathrm{sp}$ band and a much narrower $\mathrm{d}$ band, the latter being both the cohesive and adsorptive (and thereby electrocatalytic) orbital, but with much higher density of electronic states. Due to the interactive nature for adsorbing species, in which the main bonding interaction is covalent, the binding energies at the metal/vacuum and metal/liquid interfaces are comparable, whereas the $\mathrm{H}$-adatoms and $\mathrm{M}-\mathrm{OH}$ adsorption energies do not exert any significant field dependence [31]. In fact, the main reason why electrode reactions involving various adsorbed hydroxo species are potential dependent is because the electrons are taken from or stored at a different Fermi levels [44], and, consequently, for transition metals the adsorptive bond becomes stronger with a lower d-band filling [31].

Unfortunately, due to a fast-reacting and the short potential range for degenerative recombination transfer of the reversible primary into irreversible surface oxides, with a wider polarization range of the latter, all catalysts so far investigated are deprived from the theoretically possible reversible OER:

$$
2 \mathrm{M}-\mathrm{OH} \Leftrightarrow \frac{1}{2} \mathrm{O}_{2}+\mathrm{H}_{2} \mathrm{O}+2 \mathrm{M}+2 \mathrm{e}^{-}
$$

while the primary oxide can still be used to speed up and facilitate the overall ORR [1-4] and other fast reactions with aldehydes, monosaccharides, and similar species [20, 21, 38].

Nguyen van Huong et al. [45] applied electroreflectance spectroscopy for in situ interphase characterization but, alike with the STM [41], were unable to identify $\mathrm{Au}-\mathrm{OH}$ and, therefore, named the later as an invisible jellium state of the "incipient oxidation of gold" to infer on its unique and specific catalytic properties. Conway et al. [32-37] confirmed the primary oxide monolayer coverage, asserted its sublattice intercalation, even the concerted replacementturnover and thereby arising surface reconstruction, but denied the stoichiometric phase compound state in spite of its pronounced thermal stability [43]. Weaver and Hoflund [46] along with Savinova et al. [43] showed the high thermal stability of primary oxides and their incorporation into the bulk of metals.

In conclusion, the whole dynamic interactive and spillover catalytic properties of primary oxides arise from their unique specific nature and typical dipole behavior.

\subsection{Membrane Properties of Hypo-d-oxides and Primary} Oxide Spillover. Hypo-d-electronic transition metal ions usually feature several altervalent states giving rise even to interactive mixed valence compounds, such as $\mathrm{TiO}_{2} / \mathrm{WO}_{3}$, $\mathrm{TiO}_{2} / \mathrm{Nb}_{2} \mathrm{O}_{5}$, or $\mathrm{TiO}_{2} / \mathrm{Ta}_{2} \mathrm{O}_{5}$, and increase the overall spillover effect of both $\mathrm{H}$-adatoms and primary oxides. Such an oxide network, in particular of polyvalent (high altervalent capacity) hypo-d-elements, when in hydrous state behaves as an ion exchange membrane [17-20]. In fact, gels (aero- and xerogels) are biphasic systems in which solvent molecules are trapped inside an oxide network, and such a material can be considered as a water-oxide membrane composite [17-20].

Such a membrane transferring mechanism causes the following. (i) Continuous undisturbed reversible anodic transferring membrane mechanism of the altervalent changes $\mathrm{C}^{6+} \Leftrightarrow \mathrm{W}^{5+} \Leftrightarrow \mathrm{W}^{4+} \Leftrightarrow \mathrm{W}^{3+} \Leftrightarrow \mathrm{W}^{2+} \Leftrightarrow \mathrm{W}^{1+}$ and similarly so for $\mathrm{Ti}^{4+}, \mathrm{Ta}^{4+}$, and $\mathrm{Nb}^{5+}$ ) [17-20], as long as enough 
moisture supply and catalyst polarization is provided [13, 20, 21]:

$$
\begin{gathered}
\mathrm{WO}_{3}+3 \mathrm{H}_{2} \mathrm{O} \Longleftrightarrow \mathrm{W}(\mathrm{OH})_{6}, \\
\mathrm{~W}(\mathrm{OH})_{6}+\mathrm{M} \Longrightarrow \mathrm{W}(\mathrm{OH})_{5}^{+}+\mathrm{M}-\mathrm{OH}+\mathrm{e}^{-}, \\
\mathrm{W}(\mathrm{OH})_{5}^{+}+2 \mathrm{H}_{2} \mathrm{O} \Longrightarrow \mathrm{W}(\mathrm{OH})_{6}+\mathrm{H}_{3} \mathrm{O}^{+}, \\
\overline{\mathrm{M}+2 \mathrm{H}_{2} \mathrm{O} \Longleftrightarrow \mathrm{M}-\mathrm{OH}+\mathrm{H}_{3} \mathrm{O}^{+}+\mathrm{e}^{-},}
\end{gathered}
$$

Such an interchangeable mechanism imposes the anodic $\mathrm{OH}^{-}$transfer within the ion exchange membrane, yielding the consequent spillover of the interactive primary oxide $(\mathrm{M}-\mathrm{OH})$ dipoles over metallic catalyst particles (Scheme 1) [1-4]. Alternatively, (ii) cathodic spillover of $\mathrm{H}$-adatoms exerts spontaneous reduction of hydrous tungsten oxide into corresponding bronze $\left(\mathrm{Pt} / \mathrm{H}_{0.35} \mathrm{WO}_{3}\right)$. These two spillover processes are fast and reversible [7-14], so that every change of catalyst polarity imposes instantaneous altering of $\mathrm{W}$ bronze into its hydrated oxide $\left(\mathrm{W}(\mathrm{OH})_{6}\right)$ [1-3, 7-14], $\left(\mathrm{Pt} / \mathrm{H}_{0.35} \mathrm{WO}_{3} \Leftrightarrow \mathrm{Pt} / \mathrm{W}(\mathrm{OH})_{6}\right)$ and vice versa, so that such an equilibrium has typical and substantial thermodynamic sense and meaning.

The problem so far was in unattainable nanostructured Pt-bronze, the catalytic activity of which exponentially increases with decreased Pt nanosize approaching maximum at monoatomic dispersion [47]. This requirement has now been fulfilled by the grafting implementation of Pt-acac (Pt acetylacetonate) within colloidal particles of peroxopolytungstic acid $[1-3,20,21]$, niobia $\left(\mathrm{Nb}_{2} \mathrm{O}_{5}\right)$, and tantalia $\left(\mathrm{Ta}_{2} \mathrm{O}_{5}\right)$. Concerning the $\mathrm{H}$-adatoms spillover yielding the bronze state out of preceding hydrated species, Tseung et al. [48-50] has achieved the same results with macrostructured Pt electrode in the same polytungstic environment, while the definition of the bronze properties originate from Glemser and Naumann [51].

1.4. Hypo-Hyper-d-d-Interbonding Nature of Electrocatalysis for Hydrogen and Oxygen Electrode Reactions. Where then lies the link between the hypo-hyper-d-d-interelectronic bonding and SMSI synergistic electrocatalytic effects? The whole electrocatalytic theory [52] relies on the Brewer [53] intermetallic bonding model and the Friedel and Sayers [54] hypo-hyper-d-d-electronic correlations. They both infer that the stronger the $\mathrm{d}-\mathrm{d}$ intermetallic bonding, the more strengthened and exposed d orbitals within the symmetric intermetallic phases, thereby the weaker adsorptive strengths of intermediates $(\mathrm{M}-\mathrm{H}, \mathrm{M}-\mathrm{OH})$ in the RDS, therefore, the easier their cleavage, and, consequently, the higher the reaction rate and the overall catalytic activity [1-6, 20, 21]. The same Brewer- [53] type d-d intermetallic bonding model has been the already anticipated basis for Livage and Guzman [19], Neophytides et al. [20, 21], and Tauster and Fung [22] promotional strong metalsupport interaction (SMSI) effect, with the far-reaching consequences in heterogeneous catalysis, electrocatalysis. The latter systematically predetermined interactive grafting $[55,56]$ and the homogeneous, even uniform distribution of prevailing hyper-d-metallic catalysts upon hypo-d-oxide supports $[1-4,20,21]$. The same type of hypo-hyper-d-dinteractive bonding between nanostructured metal particles of such composite catalysts and their hypo-d-oxide supports additionally reinforces the entire electrocatalytic activity effect $[55,56]$. The pronounced cathodic and anodic interactive spillover (effusion) contributions within the SMSI have been significant for the present theory and its embodiment in electrocatalysis of hydrogen and oxygen electrode reactions for low- and medium-temperature (L\&MT) PEMFC and water electrolysis (WE) $[1-4,20,21]$. In aqueous media $\mathrm{Pt}(\mathrm{Pt} / \mathrm{C})$ features the catalytic surface properties of Pt$\mathrm{H}$ and $\mathrm{Pt}=\mathrm{O}$, missing any effusion of other interacting species; a new generation of composite interactive supported (SMSI) electrocatalysts in condensed wet state primarily characterizes extremely fast reversible spillover interplay of either $\mathrm{H}$-adatoms or the primary oxides ( $\mathrm{Pt}-\mathrm{OH}, \mathrm{Au}-\mathrm{OH}$ ) as the significant interactive electrocatalytic ingredients [1$4,20,21]$.

Volcano plots of various physical and chemical properties along transition series reveal the periodicity features of elements based on the d-d electronic correlations, with similar symmetric shape and, consequently, when plotted together yield various linear interdependences. As a consequence, the $d$ band of transition elements has been confirmed to play a crucial role in the bonding, adsorptive, catalytic, and electrocatalytic properties, and, consequently, any search for advances and synergism should be based on the d-d interelectronic correlations and modifications $[52,55,56]$. Such a state of theoretical knowledge and experimental evidence leads to the conclusion that every hypo-hyper$\mathrm{d}$-d interelectronic phase diagram behaves as the part of the periodic table between the two initial periods of the interacting ingredients. Their intermetallic phases are of the same average d-electronic configuration replacing the missing elements in their energy state and behaviour in between and, consequently, have been used to assess the synergistically active electrocatalysts for the hydrogen electrode reactions (Figure 1, [2]). These theoretical and experimental facts can then be employed to assess the synergistically active electrocatalysts from the peak of corresponding volcano plots along each hypo-hyper-d-d interelectronic phase diagram.

1.5. Miscellaneous Retrospects and Prospects. The present review study represents the theoretical basis of our achievements and advances in electrocatalysis for hydrogen and oxygen electrode reactions, based on individual and hypo-hyperd-d-interelectronic combinations of intermetallic phases [52], interactively supported upon corresponding hypo-doxides and leading to the reversible interrelating composite nanostructured electrocatalysts of bronze $\mathrm{Pt} / \mathrm{H}_{0.35} \mathrm{WO}_{3}$ versus its hydrated $\mathrm{Pt} / \mathrm{W}(\mathrm{OH})_{6}$ type $[1-4,20,21]$, appearing as the effect of displayed reversible spillover phenomena. In the same context, such bronze type $[1,4]$ behavior enables the development of reversibly revertible alterpolar cell between PEMFC and water electrolysis (WE), as a target objective for energy conversion, primarily enabling hydrogen production and its immediate straightforward reversal 
fueling. Such a system necessarily implies the instantaneous reversible alterpolar properties of the same electrode from hydrogen evolution (HER) to cathodic oxygen reduction (ORR), from oxygen evolution (OER) to anodic hydrogen oxidation (HOR), and vice versa. In such a context of longer stepwise development, the need for a thorough review and combination of the main successive sequential data is emphasized in order to get the final version of a specific electrocatalytic theory and discuss it in the light of new prospects and insights.

Based on the present theory, an unusual and specific PEMFC electrode assembly has been created, in which a metallic part of the interactive supported electrocatalyst $(\mathrm{Pt})$ is interconnected with two solid electrolytes: (a) Nafion-117 membrane for proton transfer after hydrogen dissociative adsorption from gas phase $(\mathrm{Pt}-\mathrm{H})$ and electrochemical desorptive charging in the subsequent step (Heyrowsky mechanism) and (b) the composite interactive hypo-doxide structure $\left(\mathrm{Pt} / \mathrm{WO}_{3}\right.$ or $\mathrm{Pt} / \mathrm{Nb}_{2} \mathrm{O}_{5}$ and/or their mixed valence compounds with $\left.\mathrm{TiO}_{2}, \mathrm{ZrO}_{2}, \mathrm{HfO}_{2}\right)$. The latter is capable for simple hydration, originating from continuous dissociative adsorption of moisture [15, 16, 57] supply (2a), followed by the hydroxide ionic migration transport under the anodic polarization field as a driving force ((2b) and (2c)) and resulting in the reversible (back and forth) primary oxide (dipole repulsion homogenized) spillover distribution all over the exposed anodic Pt surface (the overall Equation (2)), available for CO tolerance (even above $600 \mathrm{ppm}$ ). Alternatively such a spillover mechanism yields Pt-bronze as the effect of fast $\mathrm{H}$-adatoms reductive effusion at the cathode $\left(\mathrm{Pt} / \mathrm{H}_{0.35} \mathrm{WO}_{3}\right)$ during cathodic polarization [7-14].

Finally, there should be revealed one more critical view in electrocatalysis. Usually student textbooks say that the Tafel plots for the cathodic hydrogen evolution (HER) and its anodic oxidation (HOR) are symmetric and almost equal along two opposite axes. It might be so for some individual metals, but not necessarily, since the metal surface can be covered by oxides during anodic polarization. However, it is not so for the hypo-hyper-d-d-intermetallic phases and alloys. During cathodic polarization, $\mathrm{H}$-adatom intermediates keep the metallic surface free from oxides $[47,58]$ and feature maximal synergistic electrocatalytic activities [52, 59]. Figure 7 in [40] correspondingly reveals such polarization properties for Pt-Mo intermetallic phases. Meanwhile, since hypo-d-metals are hydrophilic elements and thereby sensitive on water and oxides, hypo-hyper-d-d-intermetallic catalysts feature two different electrode properties. During the cathodic polarization, hypo-d-ingredients are pulled inside the intermetallic phase or alloy, as Mavrikakis et al. $[47,58]$ have shown by DFT calculations, and H-adatoms provide pure metallic interface. In the course of anodic processes, the strong water molecule interaction draws them backwards on the catalyst's outer boundary, where they undergo the transference into surface oxides and exhibit quite different polarization properties.

The latter can be useful for the CO tolerance, while for the time being only interactive hypo-d-oxide-supported $\mathrm{Pt}$ of bronze type satisfies the fast HOR [1-4].

\section{Experimental Methods}

Experimental methods, in particular concerning novel bronze-type interactive supported electrocatalysts, their synthesis, nanostructured and surface characterization, and kinetic and electrocatalytic activity testing, were described in all necessary details in the preceding papers of the same authors $[1,4]$.

\section{Results and Discussion}

3.1. DRIFT Spectra Evidence for the Autocatalytic Water Effect in the Primary Oxide Appearance, Existence, and Spillover. DRIFT spectra reveal the steady amounts of adsorbed water and the primary oxide upon examined species by the corresponding left and right peaks, respectively. A typical example is shown in Figure 3(a) for $\mathrm{Mo} / \mathrm{TiO}_{2}$ after reduction under hydrogen at $300^{\circ} \mathrm{C}$ and exposure to $\mathrm{He}$ flow at room temperature (RT). Figure $3(\mathrm{~b})$ reveals the same thing for $\mathrm{PtMo} / \mathrm{TiO}_{2}$ at $\mathrm{He}$ flow at two different temperatures $(300$ and $350 \mathrm{~K})$, to investigate the thermal desorption effect. Finally, Figure 3(c) corresponds to the preceding issue, but the thermal effect is investigated under hydrogen flow and at the same temperatures. The striking observation is that regardless of the lack of reaction between hydrogen and water, quite distinctly from and differently to the preceding issue scanned under equal thermal conditions, both peaks disappear during the same time interval at relatively low temperature. Since the initial amount of adsorbed water is fixed, while hydrogen is continuously supplied, the conclusion is very interesting: water molecules undergo spontaneous dissociative adsorption (2a) upon anatase titania [15], and then they become the subject of both the membrane flow, ((2b) and (2c)), and Ertl's [30] autocatalytic (or self-catalytic) mechanism of $\mathrm{Pt}-\mathrm{OH}$ production (1), the latter being now reduced by $\mathrm{H}$-adatoms $(\mathrm{Pt}-\mathrm{H})$. Along with the primary oxide reduction by the hydrogen stream recombined instantaneously and spontaneously in its adatoms $(\mathrm{Pt}-\mathrm{H})$, and thereby continuous disturbance of the $\mathrm{H}_{2} \mathrm{O} / \mathrm{OH}^{*}$ equilibrium (1), the recombination of water molecules into the primary oxide proceeds spontaneously as well, as a driving force to keep the same earlier established equilibria. Thus, the experiment reveals the continuous stepwise consumption both of water and primary oxide due to their interrelating equilibrium and the occurrence of thermodynamically spontaneous reactions. Furthermore, the present DRIFT experiments testify for the existence and spontaneous establishing of the autocatalytic step of water molecules in the primary oxide growth and their equilibrium (1). Such a clear DRIFT spectra sequence seems unequivocal and unique in its sense, meaning, and significance.

3.2. Potentiodynamic Evidence of the Primary Oxide Spillover. The first experimental evidence for the fast reversible anodic adsorptive growth and corresponding cathodic desorption of the $\mathrm{Au}-\mathrm{OH}$ and $\mathrm{Pt}-\mathrm{OH}$ primary oxides, and thereby for their electrochemical spillover confirmation, is primarily owed to the excellent potentiodynamic spectra of Conway et al. [32-37]. The former by their coinciding positions along the 


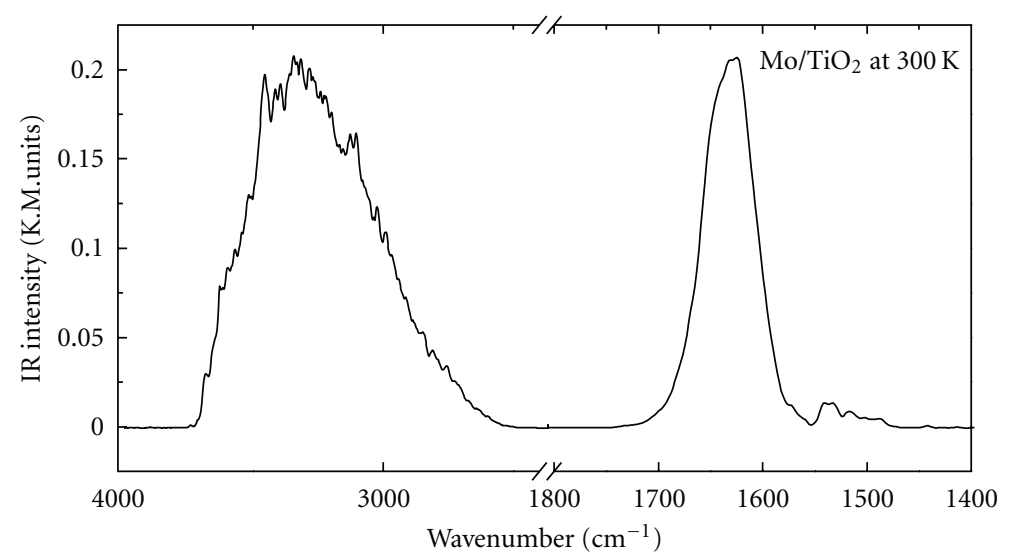

(a)

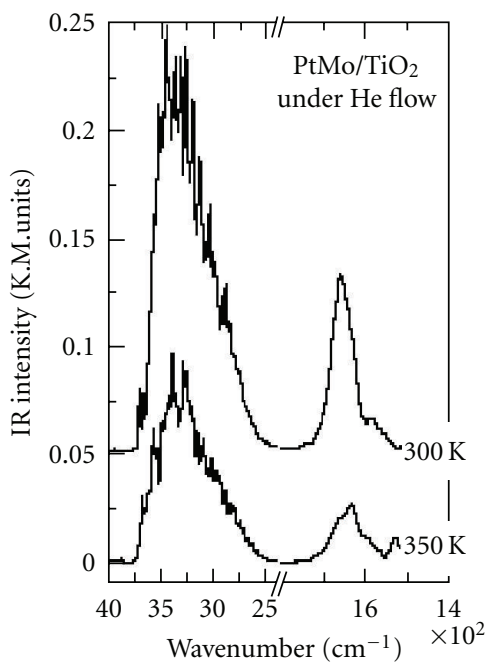

(b)

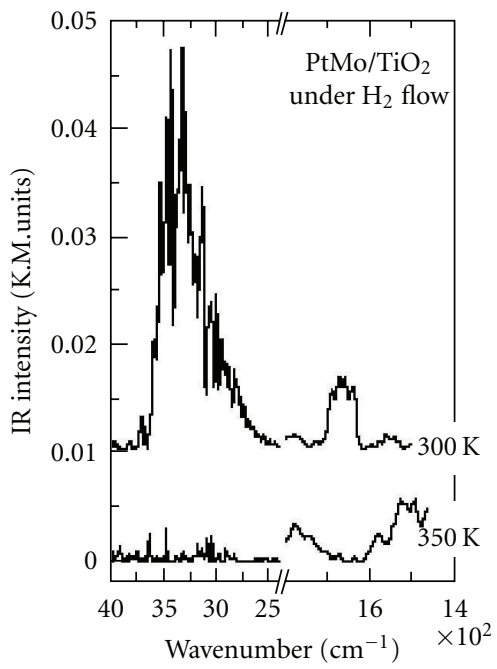

(c)

Figure 3: DRIFT spectrums for $\mathrm{H}_{2} \mathrm{O}$ and $\mathrm{M}-\mathrm{OH}$ : (a) $\mathrm{Mo} / \mathrm{TiO}_{2}$ after reduction under $\mathrm{H}_{2}$ at $300^{\circ} \mathrm{C}$ and $\mathrm{He}$ flow at RT. (b) As (a) for Pt$\mathrm{Mo} / \mathrm{TiO}_{2}$ and $\mathrm{He}$ flow at $350 \mathrm{~K}$. (c) As (b) under $\mathrm{H}_{2}$ flow. Since $\mathrm{M}-\mathrm{OH}$ becomes depleted in hydrogen flow, the same correspondingly occurs with water.

potential axis reveal the typical double layer charging and discharging features of dipolar species upon and from a capacitor. In the same sense, cyclic voltammetry has also been recalled to scan the hydroxide ions' membrane transferring effect, enabled by continuous moisture saturation feeding supply of the hypo-d-oxide support structure for composite nanostructured electrocatalysts, upon the whole reinforced primary oxide both chemisorptive generation and desorptive removal and, consequently, to record its spillover dynamics while charging and discharging of the DL capacity $[1-4,20$, 21].

In this respect an intermolecular compatible hypod-oxide composite mixed-valence architecture $(5.0 \mathrm{~mol} . \%$ $\mathrm{WO}_{3}, 95.0 \mathrm{~mol} . \% \mathrm{TiO}_{2}=20 \mathrm{wt} . \%$, along with $10.0 \mathrm{~mol} . \%$ $\mathrm{Nb}_{2} \mathrm{O}_{5}, 90.0$ mol.\% $\mathrm{TiO}_{2}=20$ wt.\%), as the interactive catalytic submonolayer support of rather high altervalent capacity, capable of withstanding alkaline media too, has been selected to investigate the primary oxide and $\mathrm{H}$-adatoms spillover properties. In this respect, cyclic voltammograms scanned upon $\mathrm{Pt} / \mathrm{WO}_{3}, \mathrm{TiO}_{2} / \mathrm{C}$ (or $\mathrm{Pt} / \mathrm{Nb}_{2} \mathrm{O}_{5}, \mathrm{TiO}_{2} / \mathrm{C}$ ) electrocatalyst at low moisture content of $\mathrm{He}$ stream (just enough to enable basic electrode processes to proceed), insufficient for $\mathrm{WO}_{3}\left(\right.$ or $\mathrm{TiO}_{2}$ ) hydration, (2a), repeatedly reveal similar potentiodynamic spectra characteristic for carbon supported Pt itself (Figure 4), but with high double layer charging capacity, because of the accompanying parallel charging of Vulcan carbon particles beside the metal $\left(Q_{D L}=1.07 \mathrm{C}\right.$, assessed by the method displayed by Schmidt et al. [60]).

In contrast to such fairly common occurrences, a continuous supply of saturated water vapor in the $\mathrm{He}$ stream at higher temperature $\left(80^{\circ} \mathrm{C}\right)$, imposing condensation (Boudart spillover precondition [7-10]) and leading to the appearance of wet titania-tungstenia mixed altervalent oxide composite, as the interactive catalytic support, has been accompanied by the unusual phenomenon of a dramatic expansion of two reversible pairs of peaks of both the primary oxide and $\mathrm{H}$-adatoms chemisorptive deposition and desorption (Figure 4). The latter have both been of 


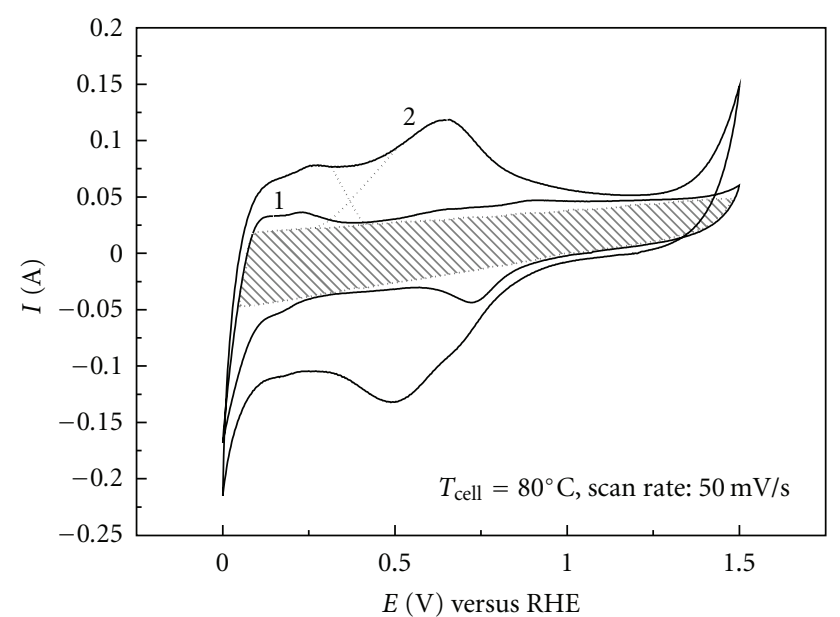

Figure 4: Cyclic voltammograms of mixed hypo-d-oxides supported nanostructured $\mathrm{Pt}$ electrode $\left(\mathrm{Pt} / \mathrm{TiO}_{2}, \mathrm{WO}_{3}\right)$, scanned in $\mathrm{He}$ stream, ones at negligible moisture content (curve 1) and at water vapor saturation (curve 2).

unusually high spillover charge and discharge capacity values and for Pt-OH (UPD and OPD) shifted towards both much more negative and far positive potential limits. In fact, the latter arises just as the effect of the primary oxide equivalent dipole charging and discharging of the double layer! Namely, just as stated above, nothing else takes place in between. Every cessation in the steam supply instantaneously imposes the sudden reversible shrinkage of both such rather exaggerated pairs of peaks down to the same initial potentiodynamic shape similar to the nanostructured $\mathrm{Pt} / \mathrm{C}$ voltammogram spectra, but only with less pronounced (UPD and OPD) extensions in the double layer where charging or discharging extends. Vice versa, the renewed saturated water vapor feeding immediately leads to their sharp former primary oxide peaks and the same former charge capacities [1-4]. Such an appearance without exception behaves as a typical reversible transient phenomenon by its endless repetition and never appears upon the plain $\mathrm{Pt} / \mathrm{C}$ electrocatalyst.

Since the two distinctly different cyclic voltammogram shapes (Figure 4) appear only as the result of the difference in water vapor supply, and other parameters being the same, an unequivocal theoretical conclusion, as well as the best heuristic experimental confirmation, has been derived from the interfering interactive character and specific inter-exchangeable double ( $\mathrm{H}$-adatoms and $\mathrm{Pt}-\mathrm{OH})$ spillover properties of a unique altervalent hypo-d-oxide structure under directional electrode features of polarized nanostructured Pt electrocatalyst. The deconvoluted cyclic voltammograms clearly reveal the mutual merging of two otherwise independent spillover peaks for both $\mathrm{Pt}-\mathrm{H}$ and $\mathrm{Pt}-\mathrm{OH}$ adsorption and desorption, with farreaching positive consequences in the revertible combination of both PEMFCs and WE $[1,4]$. The same conclusion equally concerns the equivalent combinations of $\mathrm{Nb}_{2} \mathrm{O}_{5}$ and $\mathrm{TaO}_{2}$ (even $\mathrm{MoO}_{3}$ ) with anatase titania, which at some broader ratios, when properly thermally treated, feature very high electron conductivity (above $300 \mathrm{~S} \mathrm{~cm}^{-1}$ ) and corresponding membrane transfer capability with equal dual spillover properties (absent carbon current collector). Meanwhile, the electron conductivity is a bulk property, while the membrane transfer mostly takes place above the rather developed hydrated hypo-d-oxide surface.

As a consequence, the whole phenomenon, in pronouncedly more wet condensation conditions and continuous water vapor supply, is further remarkably more facilitated both in the reversible cathodic $\mathrm{H}$-adatoms spillover yielding Pt-bronze and/or, vice versa, its anodic transfer into the hydrated state and sources $\left(\mathrm{W}(\mathrm{OH})_{6}, \mathrm{Ti}(\mathrm{OH})_{4}\right.$, $\left.\mathrm{Nb}(\mathrm{OH})_{5}, \mathrm{Ta}(\mathrm{OH})_{4}\right)$ for Pt-OH effusion, both being fast reversible reactions. Thus, the primary oxide dipole species undertake both the unusually pronounced double layer charging role and/or exaggerated UPD and OPD adsorption and corresponding desorption within much broader potential range. Consequently, the whole system behaves as pronouncedly reversible and smoothly alterpolar both for the primary oxide and $\mathrm{H}$-adatoms spillover and, as a whole, in the reversibly revertible alterpolar coexisting equilibrium interrelation between tungsten bronze and its hydrated state $\left(\mathrm{Pt} / \mathrm{H}_{0.35} \mathrm{WO}_{3} \Leftrightarrow \mathrm{Pt} / \mathrm{W}(\mathrm{OH})_{6}\right)$. In other words, two coexisting and mutually interfering reversible pairs of peaks fast altering between $\mathrm{H}$-adatoms (adsorption or desorption) effusion and $\mathrm{Pt}-\mathrm{OH}$ spillover (and/or its backwards removal) along the potential axis, with all interacting consequences imprinted upon cyclic voltammetry spectra, inherently testify by their exaggerated potentiodynamic features, to the reversible interrelations between two coherent dual alterpolar electrode properties. In addition the extremely fast $\mathrm{H}$-adatoms spillover within the hypo-d-oxide structure highly facilitates their effusion over carbon catalyst support. This experimental evidence implies the equivalence in the endlessly repeatable reversible alterpolar changes and stable electrocatalytic properties of L\&M PEMFC in conjunction with equally catalytically advanced WE, in particular important for the impurity (frequent alterpolar interchanging relation) effect of the latter. In this respect, both peaks of $\mathrm{Pt}$ $\mathrm{OH}$ adsorption and desorption are equal and of enormous charge capacity $\left(Q_{\mathrm{Pt}-\mathrm{OH}(\mathrm{a})}=Q_{\mathrm{Pt}-\mathrm{OH}(\mathrm{c})}=1.453 \mathrm{C}\right)$, like a DC capacitance of extremely developed electrode surfaces, and, since they are highly reversible, they keep the same extents even after multiple and repeating number of cycles at any other time. These experimental facts imply conclusive remarks about an already known phenomenon [11-14] that the bipolar primary oxide structure $(\mathrm{Pt}-\mathrm{OH}, \mathrm{Au}-\mathrm{OH})$ establishes the reversible transient adsorption and charging capacity even on usually developed active carbon surface $(\mathrm{C}-\mathrm{OH})$, but by no means takes place in its oxidation $[1,4]$. The latter statement has been confirmed by online mass spectrometer, which identifies $\mathrm{CO}_{2}$ only within the oxygen evolving potential limits. The fast spillover of $\mathrm{H}$-adatoms over also reversibly fast renewing tungsten bronze $\left(\mathrm{Pt} / \mathrm{H}_{0.35} \mathrm{WO}_{3}\right)$ out of its interrelating hydrated state $\left(\mathrm{Pt} / \mathrm{W}(\mathrm{OH})_{6}\right)$, including its own nonstoichiometric stored $\mathrm{H}$-amounts, along with adsorptive effusional deposition on, and subsequent desorptive removal from exposed carbon surface, in such a way, continuously behaves as its auxiliary 
storage [11-14]. The partial participation of moisture in the gas stream supply, along with the available adsorptive surface of the electrode, defines the extent of the charge capacity both for the primary oxide peak itself and double layer extension and growth, the phenomenon that has never been marked on the RDE and any other polished plain Pt-type electrodes in aqueous media. Due to the increased moisture content, now the $\mathrm{H}$-adatoms UPD desorption peaks directly merge with the prevailing broad reversible primary oxide spillover deposition and appear in dramatically expanded charge capacity (247 versus $47 \mathrm{mC} \mathrm{cm}^{-2}$ or in the ratio of about $5.3: 1)$. In fact, $0.4 \mathrm{mg} \mathrm{Pt} \mathrm{cm}^{-2}$ effectively corresponds to $200 \mathrm{~cm}^{2}$ of exposed Pt surface (BET assessed $50 \mathrm{~m}^{2} \mathrm{~g}^{-1} \mathrm{Pt}$ ) or to $42.0 \mathrm{mC} \mathrm{cm}^{-2}$ of charge capacity per projected geometric surface of electrode, in good agreement with the UPD Hadatoms determined desorption value under dry conditions. Exactly the same relates to the $\mathrm{H}$-adatoms adsorption and $\mathrm{Pt}-\mathrm{OH}$ desorption peaks in the equivalence to their corresponding reversible counterparts.

The enriched potentiodynamic experimental evidence, in accordance with the theory of instantaneous reversibly revertible alterpolar properties of the bronze-type electrocatalysts and extremely broad potential range of the primary oxide adsorption and desorption, unambiguously testifies now that the Pt-OH ( $\mathrm{AuOH}, \mathrm{M}-\mathrm{OH})$ in aqueous media both UPD and OPD charges and discharges double layer (2) and thence is available for reaction within broad potential limits. For example, formaldehyde oxidation starts exactly at its reversible potential value $(0.32 \mathrm{~V}$ versus $\mathrm{RHE})$, at the usual lower DL charging potential limits, even merges with the second UPD desorption peak of H-adatoms, and extends as an exaggerated broad twin peak all along the anodic scan until the beginning of OER (Figure 2(a)) [38], similarly and correspondingly to Figure 2(b). A similar cyclic voltammogram, in accordance with the present theoretical model and as the result of the $\mathrm{Pt}-\mathrm{OH}$ spillover effect, has also been scanned by Tseung et al. [61] for the anodic glucose oxidation on Pt-bronze microelectrode (Figure 1, [61]). In the same sense anodic CO oxidation on composite hypo-d-oxide-supported $\mathrm{Pt}$ or $\mathrm{Pt}$ and $\mathrm{Ru}$ catalysts takes place even within the usual interval of $\mathrm{H}$-adatoms desorption (see further downwards) and can even be brought with the reversible bronze-type $\mathrm{Pt}$ electrocatalyst under the conditions of initiation just above the HER (nearly at $0.0 \mathrm{~V}$ versus $\mathrm{RHE}$ ). In other words, $\mathrm{Pt}-\mathrm{OH}$ becomes available for reaction not only within its nominal reversible adsorption and desorption peak limits in regular mineral acid or base aqueous solutions, but depending on the reactant concentration, affinity, and its actual reaction rate, along a broad and extendable potential range.

3.3. Experimental Evidence for the SMSI d-d Effect. Very fine, nanosized $\mathrm{Au}$ films deposited by controlled electron beam evaporation of ultra-high-purity gold metal under high vacuum, onto stationary nanocrystalline anatase titaniacoated microscopical slides, have been employed to study both the SMSI and the spillover phenomena. The XP spectra of the $\mathrm{Au} 4 \mathrm{f}$ electrons reveal the remarkable binding energy shift (Figure 5), which provides evidence for the d-d-SMSI

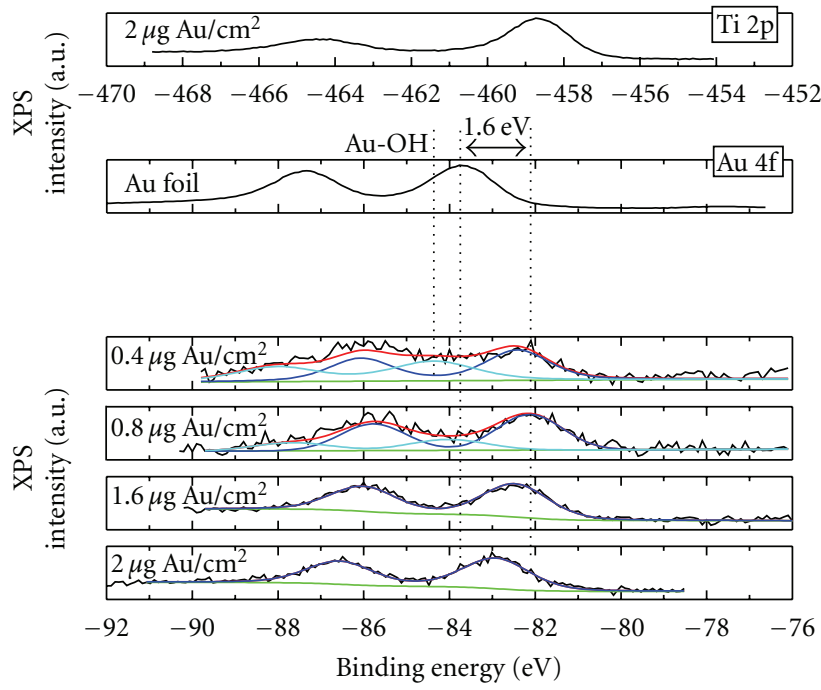

FIGURE 5: XP spectra of Au 4f for vapor-deposited nanolayered Au upon a fine thin film of anatase titania with deconvolution for lower amounts of deposits to reveal the existence of primary oxides (Au$\mathrm{OH}$ and $\mathrm{AuOOH})$ [3].

on the $\mathrm{Au} / \mathrm{TiO}_{2}$ interphase, and this has been one of the first experimental evidences of this kind in heterogeneous catalysis. The smaller the nanoparticle size or the thickness of the Au nanolayer, the larger the binding energy shift in the XP spectra with titania and the more pronounced the d-d SMSI effect, with tendency to its maximal d-d-binding strength at monoatomic dispersion and 1:1 deposition of $\mathrm{Au}$ on available $\mathrm{Ti}$ atoms, as theoretically predicted in the present and preceding papers $[2,3,20,21]$. Due to the nanodimensions of the Au layer, the signal, originated mainly from $\mathrm{Au} / \mathrm{TiO}_{2}$ interface, reflects the bonding status within the latter. In other words, the thinner the deposited $\mathrm{Au}$ nanolayer, the closer to the interphase itself $\left(\mathrm{Au} / \mathrm{TiO}_{2}\right)$ penetrate spectral beams and thereby, better and more completely reflect the bonding status within the latter.

The deconvoluted $\mathrm{Au}$ 4f peaks with lower Au loadings reveal that $\mathrm{Au}$ nanoparticles in interactive bonding contact with titania appear partially oxidized $[62,63]$. The peak located at $82.15 \pm 0.1 \mathrm{eV}$ is attributed to metallic Au, while the peak at $84.05 \pm 0.1 \mathrm{eV}$ corresponds to the gold primary (Au-OH or $\mathrm{AuOOH}$ ) oxides. The latter, in accordance with the present theory, appear as the a priori naturally provided primary oxide spillover species, associated with and promoted by the wet anatase titania interaction (2) and are, in advance, already available and ready for anodic $\mathrm{CO}$ and other oxidation processes.

Haruta et al. [64] have shown that the same reactants (propylene admixture with equimolar amounts of hydrogen and oxygen) yield different products upon different nanosized $\mathrm{Au}$ catalysts supported on anatase titania $\left(\mathrm{Au} / \mathrm{TiO}_{2}\right)$ : (i) propane by hydrogenation at nanoparticles $<2 \mathrm{~nm} \mathrm{Au}$ and (ii) propylene oxide by epoxidation or oxygen addition for $>2 \mathrm{~nm}$ Au. Hydrogenation implies H-adatoms adsorption on $\mathrm{Au}$ that should not spontaneously occur on a 


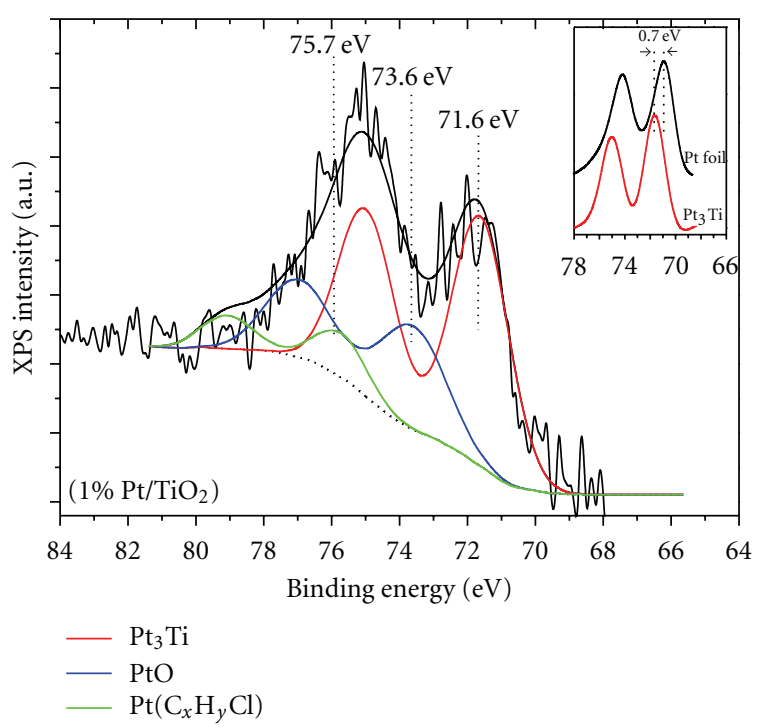

FIgURE 6: XPS 4f spectrascanned at the interphase between $\mathrm{Pt}$ catalyst (1.0 wt.\%) and interactive anatase $\mathrm{TiO}_{2}$ support in their dd-SMSI. Deconvolution exactly reveals the existence of the $\mathrm{TiPt}_{3}$ intermetallic phase at the interphase $\mathrm{Pt} / \mathrm{TiO}_{2}$ with all identified individual spectral properties, as the prerequisite for the SMSI effect.

pure massive bulky gold surface. Haruta et al. [29, 6469] ascribes such chemisorptive properties to "forced" or strained $\mathrm{Au}-d$-orbitals within smaller (below the critical threshold) nanostructured metal particles, in particular when $\mathrm{d}$-d SMSI deposited on the interactive anatase titania (cf. $[52,53,59])$. In other words, smaller nanostructured Au particles $(<2 \mathrm{~nm})$, interactively $\mathrm{d}-\mathrm{d}$ bonded with anatase titania $\left(\mathrm{Au} / \mathrm{TiO}_{2}\right)$, or in particular interactive supported upon mixed valence hypo-d-d-compounds $\left(\mathrm{Au} / \mathrm{Nb}_{2} \mathrm{O}_{5}, \mathrm{TiO}_{2}\right.$ or $\mathrm{Au} / \mathrm{WO}_{3}, \mathrm{TiO}_{2}$ ), thereby being even reinforced in their interbonding effectiveness and thence exposed with the strained d orbitals, are qualitatively different than massive Au. Such highly dispersed nanoparticles consequently behave $\mathrm{H}$-adatoms adsorption, thus feature provided the reversible behavior of hydrogen electrode in the Nernst sense [3], and, finally, are able to carry out the hydrogenation processes. It has been further shown that self-reconstructed $\mathrm{Au}$ electrode surface, after multiple potentiodynamic cycles between hydrogen and oxygen evolving limits, features the pronounced $\mathrm{H}$ adsorption and even absorption and consequently the reversible electrode properties (Krstajic et al. [3] and references therein). The reconstruction effect has been much more pronounced and faster in heavy water media, because of the stronger interatomic interrelations and deeper penetrating interphase effect of twice larger deuterium than protium ions and atoms [3].

It would be worthwhile to stress the XPS confirmation of the existence of the intermetallic phase $\mathrm{TiPt}_{3}$ within the interface contact $\mathrm{Pt} / \mathrm{TiO}_{2}$, Figure 6, as theoretically predicted by Tauster et al. [22, 23], Stevenson [24], and Haller and Resasco [25] for the prerequisite of pronounced interactive bonding (d-d SMSI) and thereby reinforcing of the entire advanced catalytic effect. In the same sense, one is still missing and looking for the confirmed existence of the $\mathrm{TiAu}_{4}$ intermetallic phase at the interface of $\mathrm{Au} / \mathrm{TiO}_{2}$.

3.4. Broader and Substantial XPS Evidence for the Primary Oxide Presence and Spillover. The link between the basic polycrystalline Pt (85\% in (111) crystal structure), as a comparative model issue, and various individual or mixed-valence hypo-d-oxide compounds $\left(\mathrm{Nb}_{2} \mathrm{O}_{5}, \mathrm{WO}_{3}\right.$, $\left.\mathrm{MoO}_{3}, \mathrm{TaO}_{2}\right)$ with anatase titania $\left(\mathrm{TiO}_{2}\right)$ itself, interactive supported nanostructured Pt electrocatalysts, imposed the imperative need for surface characterization of the latter, in particular as concerns the primary oxide $(\mathrm{Pt}-\mathrm{OH})$ spillover and $\mathrm{CO}$ tolerance $[1-3,39]$. In order to understand the origin of the oxidation states of Pt deposited on individual and/or mixed-valence hypo-d-oxide supports, in situ XP spectra of $\operatorname{Pt} 4 \mathrm{f}_{(7 / 2)}$ and $\mathrm{O} 1 \mathrm{~s}$ photoelectrons are undertaken before (Figures $7(\mathrm{a})$ and $8(\mathrm{a}))$ and after exposure in hydrogen stream at $360^{\circ} \mathrm{C}$, followed by continuous heating of the sample under $\mathrm{UH}$ vacuum, along with the examination of simple thermal effect relative to room temperature. In other words, both thermal and reactive $(\mathrm{Pt}-\mathrm{H})$ effects on the primary oxide reduction or simple desorption have been systematically XPS investigated. Consequently, XPS photoemission experiments were carried out in the specifically constructed and adjusted assembly for the present experimental purposes, which consists of a sample preparation and an analysis chamber within a high-pressure cell attached directly on the fast-entry specimen assembly for in situ XP spectra treatment in an ultrahigh vacuum (UHV) system $\left(1 \times 10^{-9} \mathrm{mbar}\right)$, the whole system being perfectly isolated from the surrounding.

In such a respect, Figures $7(\mathrm{a}), 7(\mathrm{~b}), 8(\mathrm{a})$, and $8(\mathrm{~b})$ reveal the deconvoluted $\mathrm{Pt} 4 \mathrm{f}$ and $\mathrm{O} 1 \mathrm{~s}$ XP spectra, respectively, of the $\mathrm{Pt}$ catalyst interactive supported once on the simple $\mathrm{Nb}_{2} \mathrm{O}_{5} / \mathrm{C}$ and then on mixed-valence composite $\left(\mathrm{Pt} / \mathrm{Nb}_{2} \mathrm{O}_{5}, \mathrm{TiO}_{2} / \mathrm{C}\right)$ hypo-d-oxide, scanned at room temperature (RT), distinctly after annealing under UHV conditions at $360^{\circ} \mathrm{C}$ and after the preceding reduction at the same temperature under $20 \% \mathrm{H}_{2}$ in $\mathrm{N}_{2}$ flow in the high-pressure cell attached by the fast-entry assembly to the UHV system. The shape Pt $4 \mathrm{f}$ spectra indicates the existence of more than one oxide-type Pt species and indeed, in all cases, the photopeak can be analysed into three doublets. For the analysis, the intensity ratio of the $\mathrm{Pt} 4 \mathrm{f}$ doublet components is kept at 3:4 and their splitting energy at $3.3 \mathrm{eV}$ (for a good signal-to-noise ratio, errors in peak positions were assessed to be of about $\pm 0.05 \mathrm{eV}$ ) [70]. The first component at binding energy $71.3 \mathrm{eV}$ is attributed to metallic platinum. The peak at $72.7 \mathrm{eV}$ is assigned to $\mathrm{Pt}(\mathrm{OH})_{x}(2 \leq x \leq 1)$, due to combination of $\mathrm{Pt}$ with $\mathrm{OH}$ in the primary oxide (M-OH type), or some other congenial O-species, while the third component at $74.9 \mathrm{eV}$ is ascribed to $\mathrm{PtO}_{x}$ [40], finally ending up as the stable surface oxide $\left(\mathrm{PtO}_{2}\right)$. The percentage contribution of each Pt-oxy-component to the total peak area is equivalently shown for both specimens in Table 1. As a strong XP spectral evidence for the primary oxide $(\mathrm{Pt}-\mathrm{OH})$ interactive transference (2) and existence, it is quantitatively assessed 


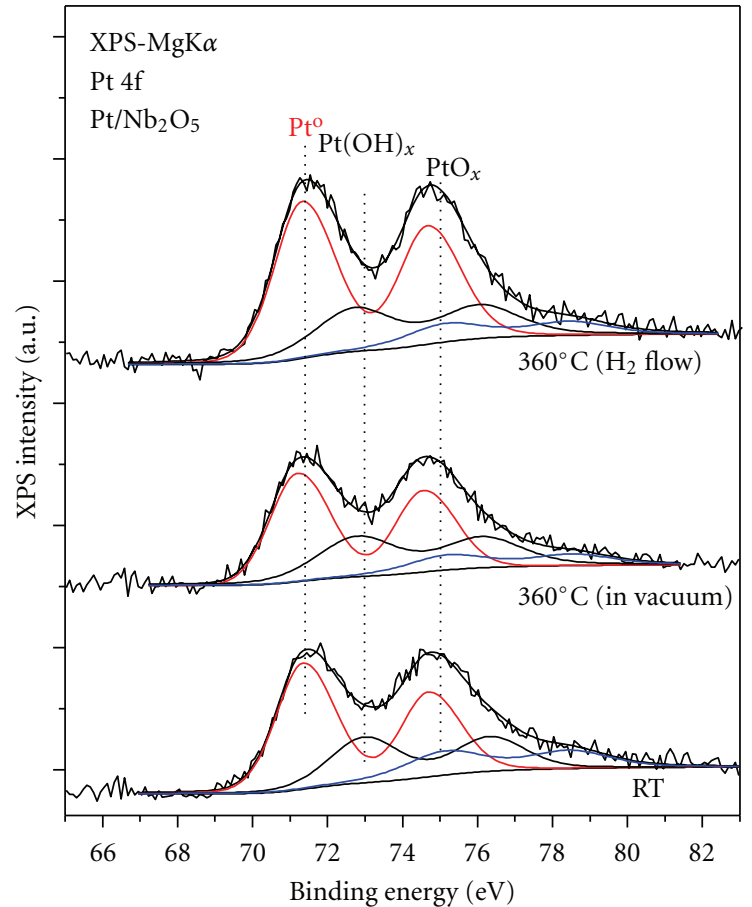

(a)

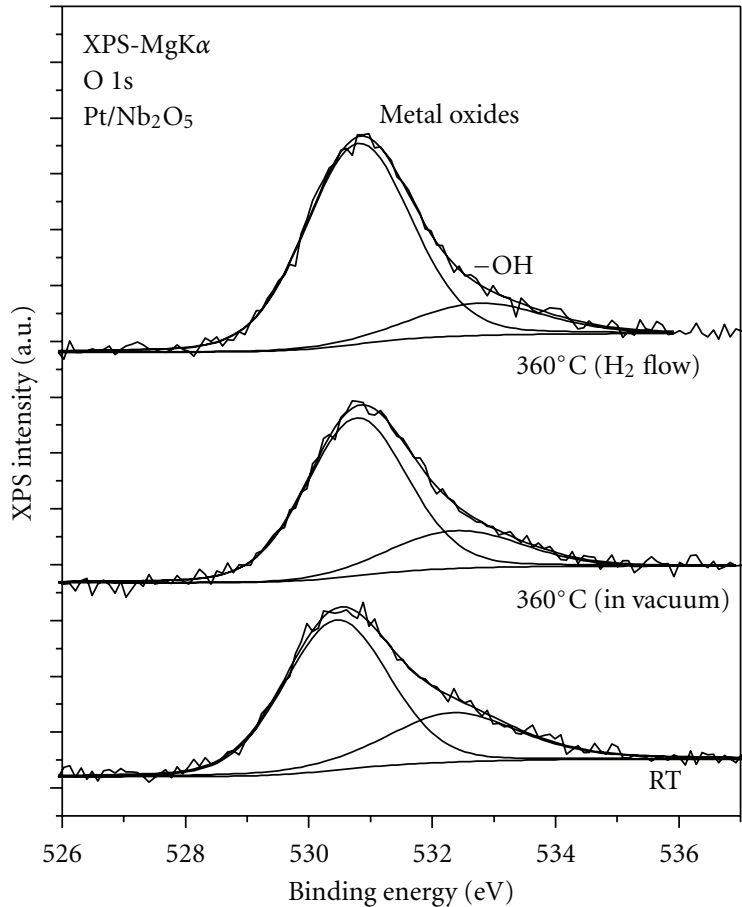

(b)

Figure 7: Pt 4f (a) and $\mathrm{O}$ 1s (b) XPS core level spectra of the Pt catalyst on $\mathrm{Nb}_{2} \mathrm{O}_{5} / \mathrm{C}$ support at room temperature (RT), after annealing under UHV conditions at $360^{\circ} \mathrm{C}$ and after reduction at $360^{\circ} \mathrm{C}$ under $20 \% \mathrm{H}_{2}$ in $\mathrm{N}_{2}$ flow.

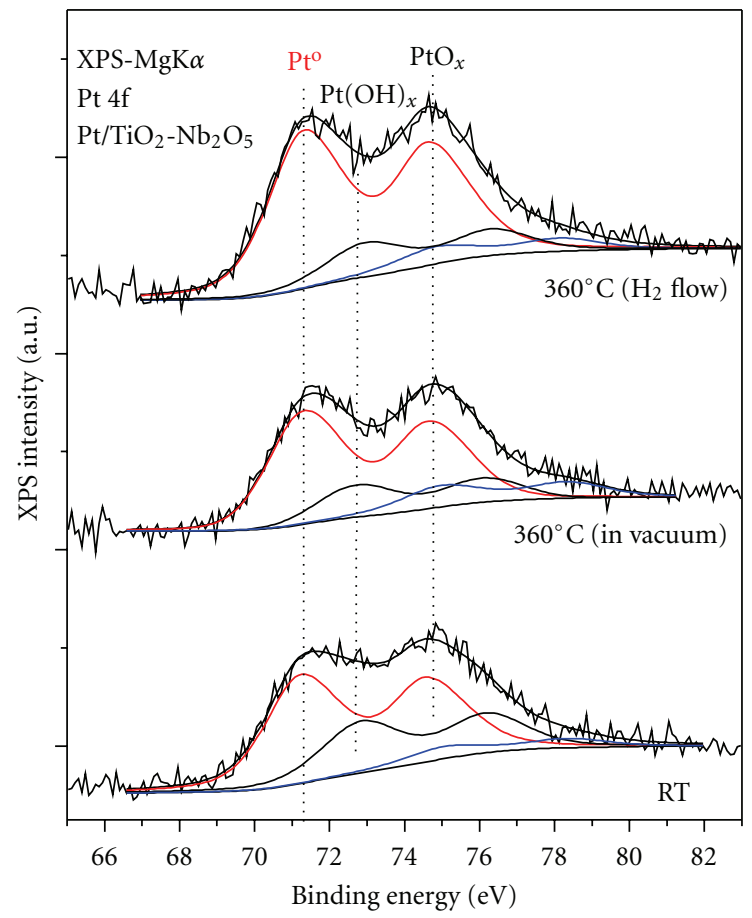

(a)

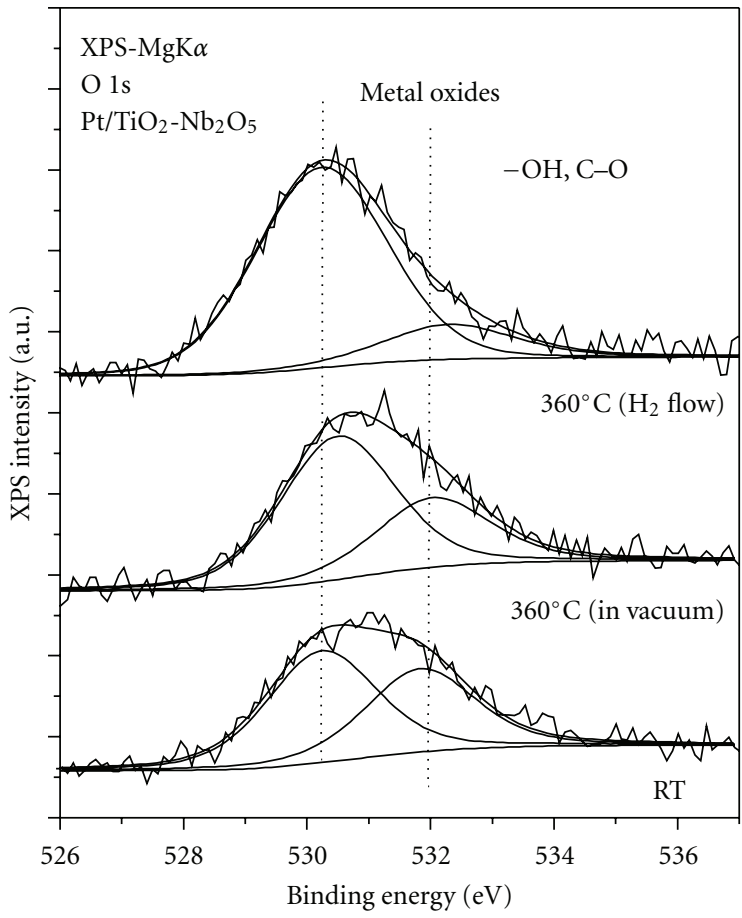

(b)

Figure 8: Pt 4f (a) and O 1s (b) XPS core level spectra of the Pt catalyst on the mixed $\mathrm{Nb}_{2} \mathrm{O}_{5}, \mathrm{TiO}_{2} / \mathrm{C}$ support at room temperature, after annealing under $\mathrm{UHV}$ conditions at $360^{\circ} \mathrm{C}$ and after reduction at $360^{\circ} \mathrm{C}$ under $20 \% \mathrm{H}_{2}$ in $\mathrm{N}_{2}$ flow. 
TABle 1: Percentage contribution of each Pt $4 \mathrm{f}$ component the total peak area.

\begin{tabular}{lcccccc}
\hline & $\begin{array}{c}\mathrm{Pt}^{2} / \mathrm{Nb}_{2} \mathrm{O}_{5}-\mathrm{TiO}_{2} \\
\mathrm{Pt}^{0}\end{array}$ & $\begin{array}{c}\mathrm{Pt}(\mathrm{OH})_{x} \\
(72.7 \mathrm{eV})\end{array}$ & $\begin{array}{c}\mathrm{PtO}_{2} \\
(74.9 \mathrm{eV})\end{array}$ & $\begin{array}{c}\mathrm{Pt}^{0} \\
(71.3 \mathrm{eV})\end{array}$ & $\begin{array}{c}\mathrm{Pt} / \mathrm{Nb}_{2} \mathrm{O}_{5} \\
\mathrm{Pt}(\mathrm{OH})_{x} \\
(72.7 \mathrm{eV})\end{array}$ & $\begin{array}{c}\mathrm{PtO}_{2} \\
(74.9 \mathrm{eV})\end{array}$ \\
\hline $\mathrm{RT}$ & 63.6 & 29.5 & 6.9 & 58.3 & 25.6 & 16.1 \\
$360^{\circ} \mathrm{C}$ in vacuum & 68.8 & 18.7 & 12.5 & 58.5 & 30.1 & 11.4 \\
$360^{\circ} \mathrm{C}$ under $\mathrm{H}_{2}$ flow & 75.9 & 16 & 8 & 71 & 19.1 & 9.8 \\
\hline
\end{tabular}

that both the simple thermal and, in particular, the annealing under hydrogen flow cause the corresponding reduction of the Pt oxy-catalyst either as the thermal desorptive effect and even more pronounced by the reactive contribution of Pt-H itself. Similar experimental evidence has already been observed on the simple basic anatase titania $\left(\mathrm{Pt} / \mathrm{TiO}_{2}\right.$, Figure 4, [2]) interactive supported Pt electrocatalyst [2, 3, $39,40]$. Furthermore, a thorough examination of the $\mathrm{O}$ $1 \mathrm{~s}$ spectra shows a pronounced decrease of the component attributed to the $\mathrm{Pt}-\mathrm{OH}$ species $(\mathrm{BE} \sim 533 \mathrm{eV})$, which apparently contradicts the enrichment in $\mathrm{Pt}(\mathrm{OH})_{x}$ amounts, observed from the Pt $4 \mathrm{f}$ spectrum. In other words, whilst the annealing causes a straight reduction of $\mathrm{Pt}$ oxi-species and desorption of the primary oxide $(\mathrm{Pt}-\mathrm{OH})$, the intensity decrease of the $\mathrm{O} 1 \mathrm{~s}$ component attributed to the same $\mathrm{OH}^{*}$ species might be compensated by the spillover from the enriched mixed-valence hypo-d-oxide support. Meanwhile, all XP spectra distinctly indicate the existence, desorptive and/or reactive removal, and compensating spillover of the primary oxide. In any case, the $\mathrm{O} 1 \mathrm{~s}$ spectrum reveals a larger initial partial amounts of the primary oxide and similar reactive oxi-species $\left(\mathrm{Pt}(\mathrm{OH})_{x}\right)$ for the issues of mixedvalence interactive supported electrocatalysts. As a whole, the annealing in vacuum causes a distinct reduction of platinum oxi-species, in particular the decrease of the primary-type $\mathrm{Pt}(\mathrm{OH})_{x}$ oxides and a slight increase of initially present (long term of the storage nucleation aging effect) $\mathrm{PtO}_{x}$. At the same time the $\mathrm{O}$ 1s component attributed to $\mathrm{OH}$ species correspondingly decreases, indicating the significant desorption of hydroxyl groups in particular pronounced from the mixed valence hypo-d-oxide supports during annealing, as the strong clear evidence for the primaryoxide-enriched presence and spillover.

XP spectral ex situ measurements, Figures 9(a) and 9(b), reveal the corresponding $\mathrm{Pt} 4 \mathrm{f}$ deconvoluted spectra of the originally freshly prepared $\mathrm{Nb}_{2} \mathrm{O}_{5}, \mathrm{TiO}_{2}-\mathrm{Nb}_{2} \mathrm{O}_{5}, \mathrm{TiO}_{2}-\mathrm{WO}_{3}$, and $\mathrm{TiO}_{2}$ itself, interactive supported Pt electrocatalysts, and for the same specimens after an annual storage. Three distinct components, just as above, participate within the electrocatalytic surface, appearing at three different binding photopeaks, 71.1, 72.7, and $74.8 \mathrm{eV}$ and in this order are correspondingly attributed to the metallic platinum itself, the primary $(\mathrm{Pt}-(\mathrm{OH}))$, and nonstoichiometric $\mathrm{PtO}_{x}$ oxides $(1 \leq x \leq 2)$, ending with the surface oxide as a final oxidation state $[2,3]$, respectively, (compare Figure 10, [3]). The latter arises as the minor component amongst others and does not even appear at the $\mathrm{Pt} 4 \mathrm{f}$ spectrum of the freshly prepared $\mathrm{Nb}_{2} \mathrm{O}_{5}-\mathrm{TiO}_{2}$-supported $\mathrm{Pt}$ catalyst after repeating scans within a longer period (Figure 9(a)). Such a decisive and conclusive remark is of substantial and fundamental significance for the present study: the primary oxide is initially available, in particular, in the condensed wet state of the electrocatalysts. In this respect, one should recall the self-catalytic effect of water molecules on the primary oxide appearance and existence [30].

The percentage contribution of each component to the total peak area is shown in Table 2(a), which has some deeper theoretical significance. The roots and expectancies for the primary oxide spillover are indicated there on an almost quantitative-scale basis. The decisive and pronounced cooperative effect of anatase titania is clearly indicated by its individual rather high initial primary oxide surface percentage, while the $\mathrm{Pt} / \mathrm{Nb}_{2} \mathrm{O}_{5}, \mathrm{TiO}_{2}$ features the most creative synergistic properties for the $\mathrm{Pt}-\mathrm{OH}$ generation that further reflects on and definitely defines the overall electrocatalytic activity for the ORR [1]. In the same context, one should mention the shrinkage of the same XPS Pt-OH peak capacity both by the thermal and hydrogen reduction effect at higher $\left(360^{\circ} \mathrm{C}\right)$ temperature (Figures $7(\mathrm{a}), 7(\mathrm{~b})$, $8(\mathrm{a})$, and $8(\mathrm{~b})$; see also Figure $4,[2])$, as the additional experimental evidence for the existence of primary oxide available for further instantaneous spillover distribution under electrode polarization. In the same respect, the complementary DRIFT imprints in Figure 3 in a similar manner reveal the same primary oxide thermal and $\mathrm{Pt}-\mathrm{H}$ reduction features, but the desorption effect in the present XPS issues arises proportionally smaller since under UHV the examined specimens are deprived from water molecules. Meanwhile, the same specimens after unused storage show the nucleation of $\mathrm{PtO}_{x}$, ending with $\mathrm{PtO}_{2}$ (Figure 9(b)), as the common transient in particular pronounced with more active interactive supported electrocatalysts [1-4].

In Figure 10 the deconvoluted $\mathrm{Ti} 2 \mathrm{p}$ spectra of $\mathrm{TiO}_{2}$ $\mathrm{Nb}_{2} \mathrm{O}_{5}$ - and $\mathrm{TiO}_{2}$-supported $\mathrm{Pt}$ catalysts are comparatively presented. The main doublet in both spectra, at binding energy ( $\left.\mathrm{Ti} 2 \mathrm{p}_{3 / 2}\right) 458.8 \mathrm{eV}$, is attributed to $\mathrm{Ti}^{4+}$ species [71, 72]. In the case of the $\mathrm{TiO}_{2}-\mathrm{Nb}_{2} \mathrm{O}_{5}$ mixed support, a second doublet is apparent at binding energy (Ti2p3/2) $455 \mathrm{eV}$. This is attributed to the contribution of $\mathrm{Ti}$ atoms in the $\mathrm{Ti}^{3+}$ state. It should be inferred here that $\mathrm{Ti}$ atoms in the other mixed hypo-d-oxide support $\mathrm{TiO}_{2}-\mathrm{WO}_{3}$ are detected only in the $\mathrm{Ti}^{4+}$ state [73].

In Figure 11 the deconvoluted Nb 3d XPS core level spectra of $\mathrm{TiO}_{2}-\mathrm{Nb}_{2} \mathrm{O}_{5}$ - and $\mathrm{Nb}_{2} \mathrm{O}_{5}$-supported Pt catalysts are presented. In both cases only one doublet is apparent at binding energy $\left(\mathrm{Nb} 3 \mathrm{~d}_{5 / 2}\right) 207.1 \mathrm{eV}$, which is characteristic 


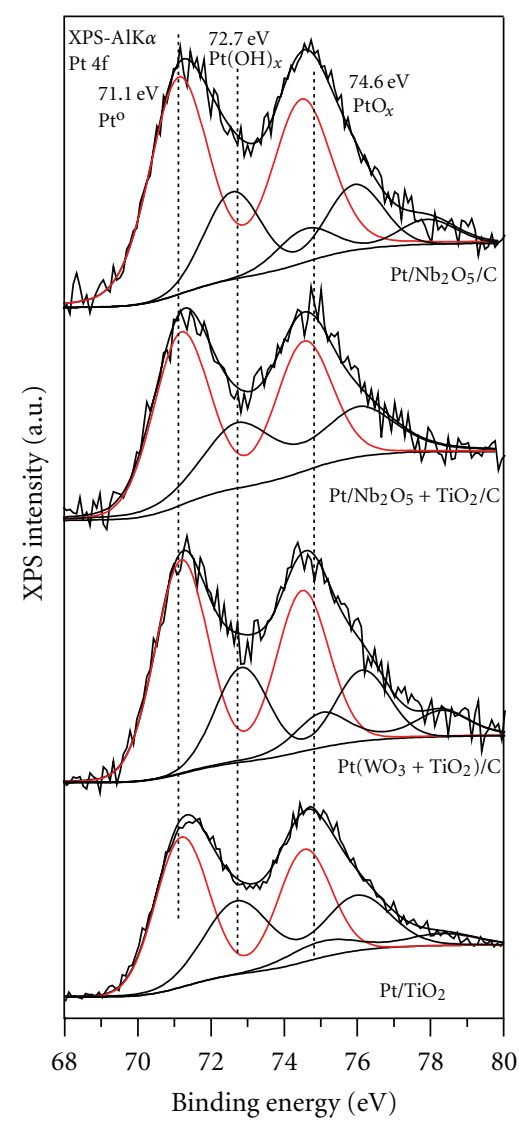

(a)

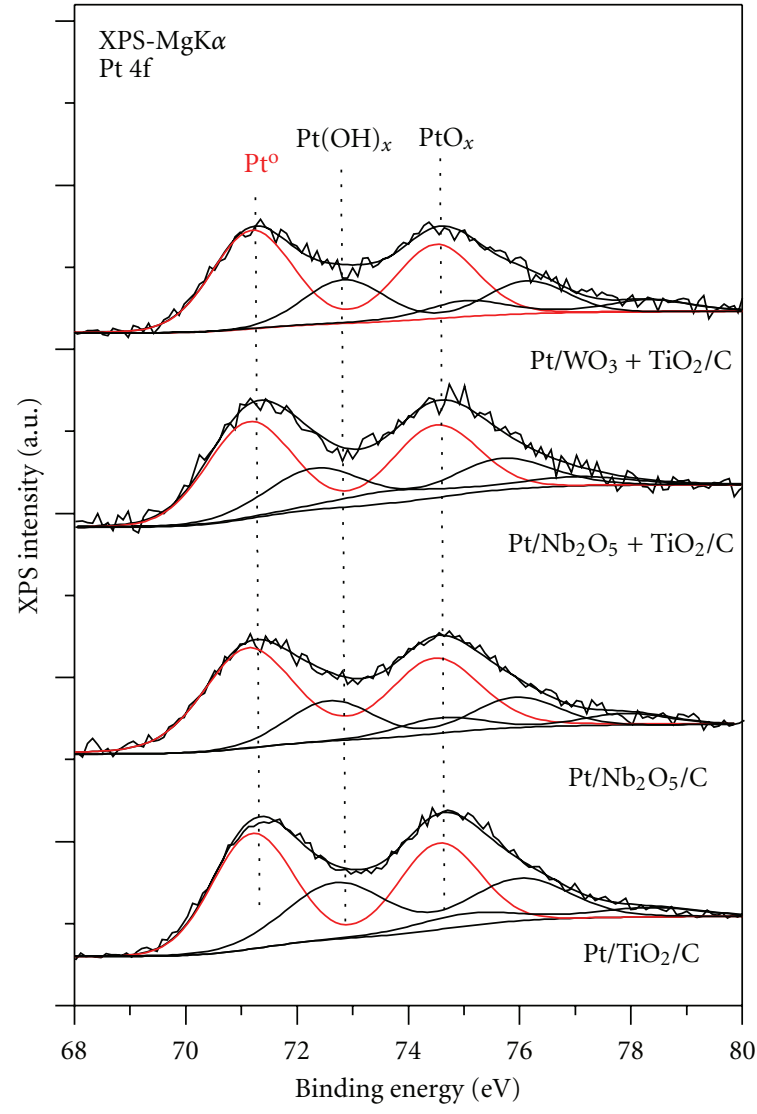

(b)

Figure 9: Pt 4f XPS core level spectra of $\mathrm{Nb}_{2} \mathrm{O}_{5^{-}}, \mathrm{TiO}_{2}-\mathrm{Nb}_{2} \mathrm{O}_{5^{-}}, \mathrm{TiO}_{2}-\mathrm{WO}_{3^{-}}$, and $\mathrm{TiO}_{2}$-supported Pt catalysts at room temperature: (a) scanned fresh and (b) after aging of one year.

for the $\mathrm{Nb}^{5+}$ state. Namely, it is found in the literature and well known that $\mathrm{Nb}^{5+}$, when inserted into a titanium dioxide network, usually causes an effect in the charge compensation [74]. The addition of such a charge can be compensated either by creating one vacancy of Ti per four introduced $\mathrm{Nb}$ ions or by the reduction of $\mathrm{Ti}^{4+}$ to $\mathrm{Ti}^{3+}$ per each inserted $\mathrm{Nb}^{5+}$ ion. Both of these effects can occur, with the latter being much more likely at relatively high temperatures [74]. Quantitative analysis of the present results, using the Ti $2 \mathrm{p}$ and $\mathrm{Nb} 3 \mathrm{~d}$ peak intensities (areas) corrected by the atomic sensitivity factors [75], shows that the appearance of each $\mathrm{Ti}^{3+}$ corresponds to one introduced $\mathrm{Nb}^{5+}$ ion. Thus, in the present case and in agreement with the existing literature, it seems that the introduction of $\mathrm{Nb}$ oxide into the composite altervalent mixed compound network with anatase titania causes the partial reduction of $\mathrm{Ti}^{4+}$ to $\mathrm{Ti}^{3+}$ per $\mathrm{Nb}^{5+}$ ion introduced and perfectly suits the relevant cooperative membrane transferring mechanism (2) [76, 77].

Now, there arises a very interesting situation concerning the most promising electrocatalytic $\mathrm{Nb}$-oxide structure, which at relatively low temperatures of calcination crystallizes as $\mathrm{Nb}_{2} \mathrm{O}_{5}$. The latter is well confirmed by the XPS analysis, while much more stable $\mathrm{NbO}_{2}$ appears above $900^{\circ} \mathrm{C}$. Such experimental evidence reveals the fifth hydroxide
$\left(\mathrm{OH}^{-}\right)$ion for the most easily transferable within the overall spillover mechanism:

$$
\mathrm{Nb}(\mathrm{OH})_{5}+\mathrm{Pt} \Leftrightarrow \mathrm{Nb}(\mathrm{OH})_{4}{ }^{+}+\mathrm{Pt}-\mathrm{OH}+\mathrm{e}^{-} .
$$

Meanwhile, XPS analysis has also revealed a further interrelating mechanism of similar exchanges with hydrated anatase titania:

$$
\mathrm{Nb}(\mathrm{OH})_{4}{ }^{+}+\mathrm{Ti}(\mathrm{OH})_{4} \Longrightarrow \mathrm{Nb}(\mathrm{OH})_{5}+\mathrm{Ti}(\mathrm{OH})_{3}{ }^{+}
$$

or, when summed up,

$$
\mathrm{Ti}(\mathrm{OH})_{4}+\mathrm{Pt} \Leftrightarrow \mathrm{Ti}(\mathrm{OH})_{3}{ }^{+}+\mathrm{Pt}-\mathrm{OH}+\mathrm{e}^{-}
$$

the entire formalism clears up the equivalence and mutual facilitation between titania and niobia for the primary oxide spillover, as already concluded from Table 2(a).

3.5. FTIR Spectroscopy Evidence of the Primary Oxide Spillover Effect. FTIR spectroscopy has also been employed for the investigation of the primary oxide spillover contribution to CO tolerance [39] from the quantitative study of CO adsorption/desorption properties, as a function of temperature and the type of the interactive hypo-d-oxide-supported 


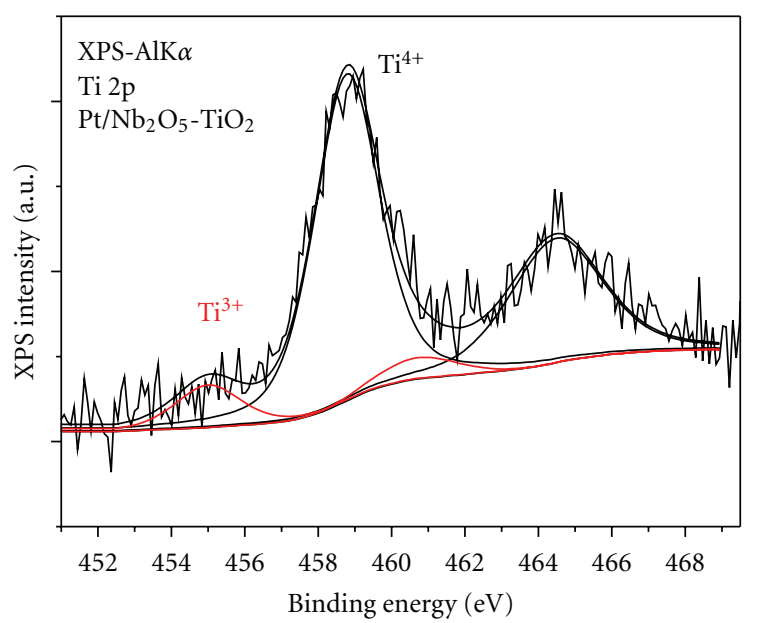

(a)

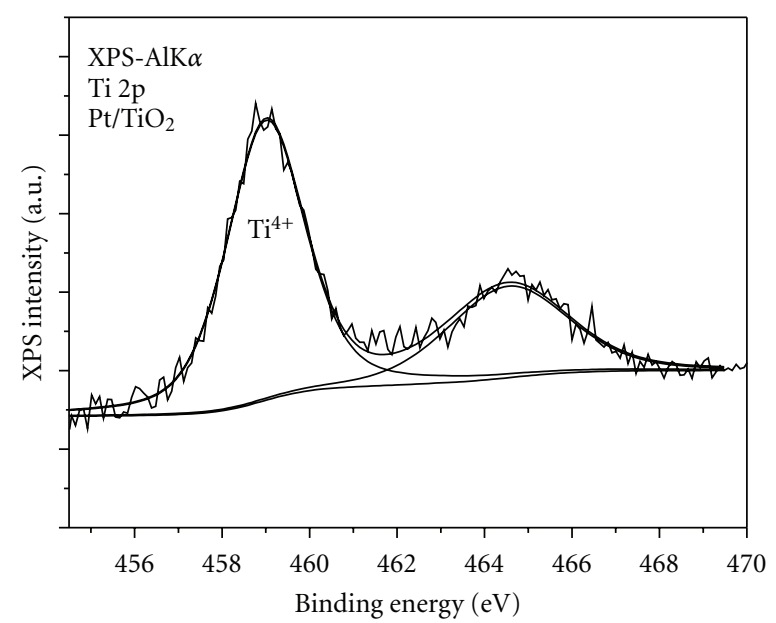

(b)

Figure 10: Deconvoluted Ti 2p XPS core level spectra of $\mathrm{TiO}_{2}-\mathrm{Nb}_{2} \mathrm{O}_{5^{-}}$(a) and $\mathrm{TiO}_{2}-$ (b) supported Pt catalysts.

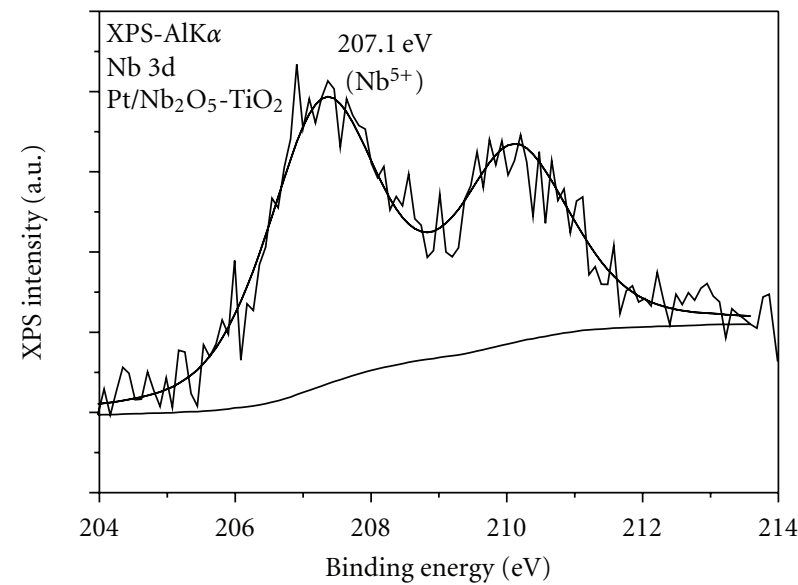

(a)

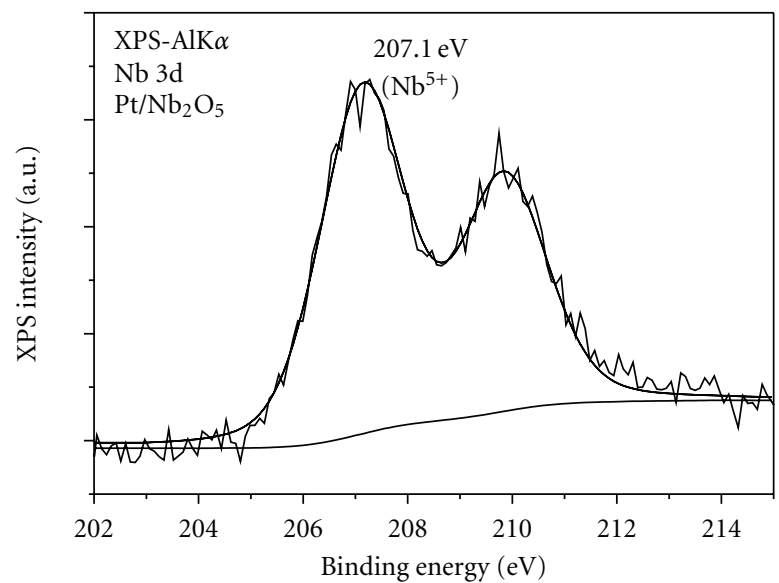

(b)

Figure 11: Deconvoluted Nb 3d XPS core level spectra of $\mathrm{TiO}_{2}-\mathrm{Nb}_{2} \mathrm{O}_{5}-(\mathrm{a})$ and $\mathrm{TiO}_{2}-(\mathrm{b})$ supported Pt catalysts.

composite electrocatalysts. In other words, the purpose was to get insights about the primary oxide effect indirectly from FTIR investigations of achieved CO tolerance. Namely, to reveal the trends in $\mathrm{CO}$ coverage amongst the different electrocatalytic specimens during the linear ramping of temperature in He stream, the ratios of the linearly desorbed CO IR band intensity, at a given temperature to the higher IR band intensity $\left(I_{\text {rel }}\right)$, are displayed in Figure 12, as a relative coverage of the linearly coordinated CO to Pt sites, labeled as the $\mathrm{CO}_{\mathrm{L}}$ species at each temperature. For monometallic supported $\mathrm{Pt} / \mathrm{TiO}_{2}$ catalyst, $I_{\text {rel }}$ passes through a maximum at $360 \mathrm{~K}$ and declines monotonically thereafter approaching zero in $\mathrm{CO}$ adsorption at $500 \mathrm{~K}$, while its derivative of the $\left(1-I_{\text {rel }}\right)$ curve features maximum in $\mathrm{CO}_{\mathrm{L}}$ desorption at $420 \mathrm{~K}$ (inset of Figure 12). Contrary to $\mathrm{Pt} / \mathrm{TiO}_{2}$, interactive supported $\mathrm{MoPt}_{x} / \mathrm{TiO}_{2}(x=1,2,3,4)$ catalysts exhibit significantly different curve profiles, which correspond to much faster $\mathrm{CO}_{\mathrm{L}}$ depletion (or much more facilitated oxidation by the primary oxide) rate. In particular, the $\mathrm{CO}_{\mathrm{L}}$ area decreases steadily without featuring any initial increasing stage or any inflection point, while complete desorption of $\mathrm{CO}$ is observed already at $370 \mathrm{~K}$. In addition, the profiles obtained from the various catalysts with different $\mathrm{Mo} / \mathrm{Pt}$ atomic ratios are quite similar, indicating that this factor is not decisive for the $\mathrm{CO}_{\mathrm{L}}$ desorption profiles. Meanwhile, it would be noteworthy that, in hydrogen gas stream, the lowest desorption temperature features the sample with the lowest Mo atomic percentage $\left(\mathrm{MoPt}_{4} / \mathrm{TiO}_{2}\right)$ [39] or the most active intermetallic phase $\left(\mathrm{MoPt}_{4}\right)$ for the HER [40]. As a difference with $\mathrm{He}$ atmosphere, $\mathrm{H}$-adatoms consume corresponding amount of the primary oxide (Pt-OH), enabling thereby the higher coverages by $\mathrm{CO}$, and consequently the desorption temperature of the latter increases, while $\mathrm{CO}$ tolerance proportionally decreases. Such observations agree quite well with the above-displayed DRIFT spectra obtained under similar conditions, in particular as concerns the interrelating hydrogen reduction effect for the primary oxide removal. In such a context, Figure 12 illustrates adsorptive-desorptive 


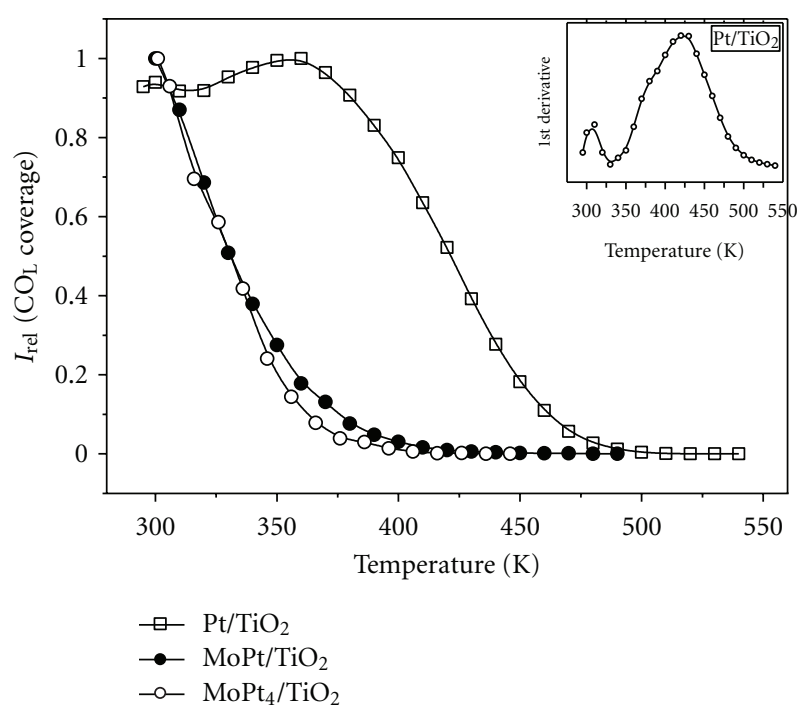

Figure 12: The linearly coordinated CO to Pt sites, $\left(\mathrm{CO}_{\mathrm{L}}\right)$, peak areas normalised to the higher measured intensity as a function of annealing temperature for $\mathrm{Pt}, \mathrm{MoPt}$, and $\mathrm{MoPt}_{4}$ supported on $\mathrm{TiO}_{2}$ catalysts. Initially the samples were exposed to $7 \% \mathrm{CO} / \mathrm{He}$ for $30 \mathrm{~min}$, and then annealing was carried out under He flow over the catalyst. Inset: peak area derivative of $\mathrm{Pt} / \mathrm{TiO}_{2} \mathrm{TPD}$ curve.

Table 2: (a) Percentage contribution of each Pt $4 \mathrm{f}$ component to the total peak area for freshly prepared specimens. (b) The same for an annual storage of the same specimens.

(a)

\begin{tabular}{lccc}
\hline & \multicolumn{3}{c}{ Percentage contribution of Pt 4 f components } \\
Catalyst support & $\begin{array}{c}\mathrm{Pt}^{0} \\
(71.1 \mathrm{eV})\end{array}$ & $\begin{array}{c}\mathrm{Pt}(\mathrm{OH}) \\
(72.7 \mathrm{eV})\end{array}$ & $\begin{array}{c}\mathrm{PtO}_{x} \\
(74.8 \mathrm{eV})\end{array}$ \\
\hline $\mathrm{Nb}_{2} \mathrm{O}_{5}$ & $67.2 \%$ & $23.7 \%$ & $9.1 \%$ \\
$\mathrm{Nb}_{2} \mathrm{O}_{5}-\mathrm{TiO}_{2}$ & $65.3 \%$ & $34.7 \%$ & - \\
$\mathrm{WO}_{3}-\mathrm{TiO}_{2}$ & $61.9 \%$ & $26.7 \%$ & $11.4 \%$ \\
$\mathrm{TiO}_{2}$ & $56.8 \%$ & $31.9 \%$ & $11.3 \%$ \\
\hline
\end{tabular}

(b)

\begin{tabular}{lccc}
\hline & \multicolumn{3}{c}{ Percentage contribution of Pt 4 f components } \\
Catalyst support & $\begin{array}{c}\mathrm{Pt}^{0} \\
(71.1 \mathrm{eV})\end{array}$ & $\begin{array}{c}\mathrm{Pt}(\mathrm{OH})_{x} \\
(72.7 \mathrm{eV})\end{array}$ & $\begin{array}{c}\mathrm{PtO}_{x} \\
(74.8 \mathrm{eV})\end{array}$ \\
\hline $\mathrm{Nb}_{2} \mathrm{O}_{5}$ & $58.3 \%$ & $25.6 \%$ & $16.1 \%$ \\
$\mathrm{Nb}_{2} \mathrm{O}_{5}-\mathrm{TiO}_{2}$ & $63.6 \%$ & $29.5 \%$ & $6.9 \%$ \\
$\mathrm{WO}_{3}-\mathrm{TiO}_{2}$ & $61.9 \%$ & $26.7 \%$ & $11.4 \%$ \\
$\mathrm{TiO}_{2}$ & $56.8 \%$ & $31.9 \%$ & $11.3 \%$ \\
\hline
\end{tabular}

properties of various examined catalyst specimens versus $\mathrm{CO}$ and thereby reflects a relative measure of their $\mathrm{CO}$ tolerance or, vice versa, the effect of the primary oxide on the latter. The lower CO desorption temperature has been attributed to its chemical oxidation at the boundaries of the Mo oxide nanoclusters by the $\mathrm{OH}^{*}$ species spillover supplied by either $\mathrm{Pt}-\mathrm{OH}$ or $\mathrm{MoO}_{2} \mathrm{OH}$, the latter being a priori ex situ already detected by XPS as the most abundant oxidation state [39, 40].
3.6. Electrocatalysis and d-Electronic Density of States versus the Fermi Level. The electrocatalytic reaction mechanism by $a b$ initio DFT calculation, both for the HER and ORR, implies that a $\mathrm{d}$ band centered near the Fermi level $\left(E_{F}\right)$ can lower the activation energy as the bonding orbital passes $E_{F}$, the critical step for reduction processes taking place when the antibonding orbital passes the Fermi level of the metal from above and picks up electrons to become filled [78, 79]. In electrooxidation reactions (HOR, OER), it is the bonding orbital that passes the Fermi level from below and gets emptied. Consequently, a good catalyst for these reactions should have a high density of $\mathrm{d}$ states near the Fermi level $[44,80,81]$. Thus, the present concept consists of the proper hypo-hyper-d-d-interelectronic combinations of transition elements both being of rather high densities of $d$ states at the Fermi level (Figure 13), in which hypo-d-oxide components (W, Nb, Ta, Ti), beside the substantially high SMSI bonding effect, as typical oxophilic d metals, in addition involve their pronounced membrane spillover properties for the primary oxide transferring and effusion. In such a state, our aim has been to keep the composite transition element ingredients with their initial high densities of $d$ states, or even to increase the latter by their SMSI interbonding effect, and at the same time to use the benefits of the primary oxide spillover for the overall reaction, in particular for the ORR. In this respect, Figure 13(b) reveals why $\mathrm{Nb}$ and $\mathrm{Ta}$, by the position in the periodic table of elements, are electrocatalytically predestined for even higher activity than $\mathrm{W}, \mathrm{Mo}$, and Ti.

3.7. Striping Voltammetry Evidence for the Primary Oxide Spillover Effect. Interactive hypo-d-oxide-supported and nonsupported electrocatalysts (both $\mathrm{Pt}$ and $\mathrm{RuPt}$ ) exhibit dramatically different activity for CO tolerance in LT PEMFC and provide new additional and indirect potentiodynamic evidence for the $\mathrm{M}-\mathrm{OH}$ spillover effect $[2,3]$. Namely, ever since Watanabe and Motoo [82] have shown that $\mathrm{Ru}$ even at submonolayer core-shell deposit, or while alloying with $\mathrm{Pt}$, shifts the primary oxide growth to a much more negative potential range and enables CO tolerance, the primary oxide spillover became of substantial significance for PEMFC [83]. Similarly, the hypo- $d$-oxide-supported Pt and $\mathrm{Ru}\left(\mathrm{Pt} / \mathrm{TiO}_{2} / \mathrm{C}, \mathrm{Ru} / \mathrm{TiO}_{2} / \mathrm{C}\right)$ in their behavior versus these two pure metals $(\mathrm{Pt} / \mathrm{C}, \mathrm{Ru} / \mathrm{C})$ themselves or even their alloys, $\mathrm{RuPt} / \mathrm{C}$ and $\mathrm{RuPt} / \mathrm{TiO}_{2} / \mathrm{C}$, have distinctly different catalytic properties, too, the interactive alternatives featuring an even more advanced and much more pronounced primary oxide spillover effect [1-4]. Since hypo- $d$-oxides, primarily anatase titania, zirconia and hafnia, and even more so tungstenia, niobia and tantalia, facilitate the spillover of $\mathrm{M}-\mathrm{OH}$, such facts clearly point to the advanced overall composite effect and advantages of membrane-type $\mathrm{OH}^{-}$transferring within $\mathrm{TiO}_{2}, \mathrm{WO}_{3}, \mathrm{Nb}_{2} \mathrm{O}_{5}$, and $\mathrm{TaO}_{2}$ and, in particular, within their mixed networks of altervalent catalyst support, resulting in the speeded-up primary oxide effusion, relative to the plain carbon $(\mathrm{Pt} / \mathrm{C})$.

In other words, while $\mathrm{Ru}$ itself facilitates $\mathrm{Pt}-\mathrm{OH}$ and $\mathrm{Ru}-\mathrm{OH}$ spillover transfer in RuPt composite electrocatalyst $[82,83]$, the supporting effusion effect of titania advances the 


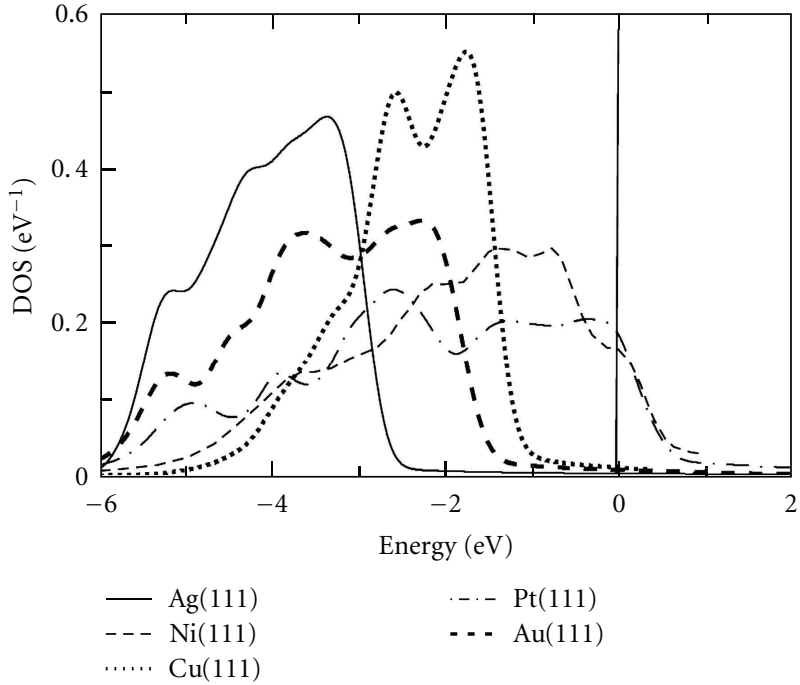

(a)

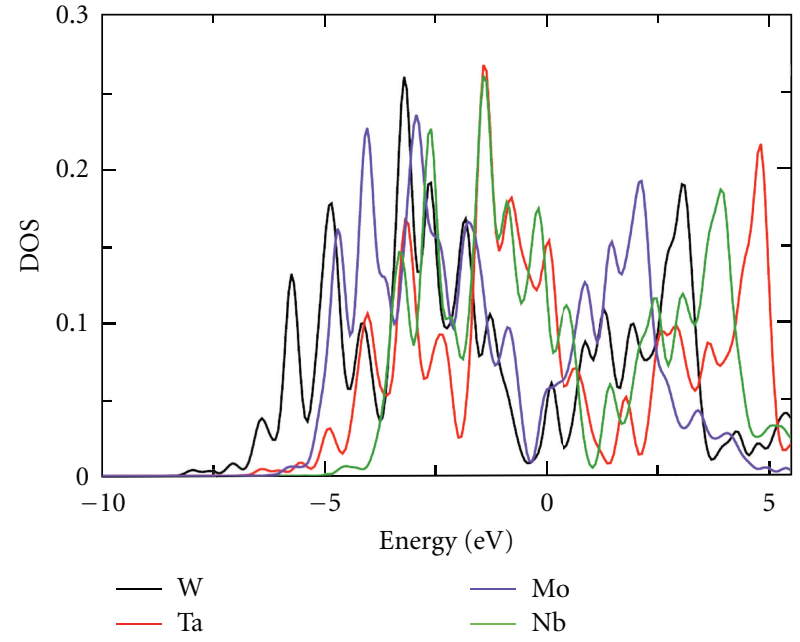

(b)

FIgURE 13: (a) Surface densities of d-band states of some selected hyper-d-electronic transition metals. The integral over the densities has been normalized to unity; the vertical line indicates the Fermi level. Indications and labels: dashed-dotted line: Pt (111); thick line: Au (111); thin line: $\mathrm{Ag}$ (111); dotted line: $\mathrm{Cu}$ (111); dashed line: Ni (111). (b) Lower location: surface densities of d-band states (bulk values differing from exact surface densities for less than 3\%) of some selected hypo-d-electronic transition metals (W, Ta, Mo, Nb, color labeled). (Calculated by Professor Wolfgang Schmickler, University of Ulm, Germany.)

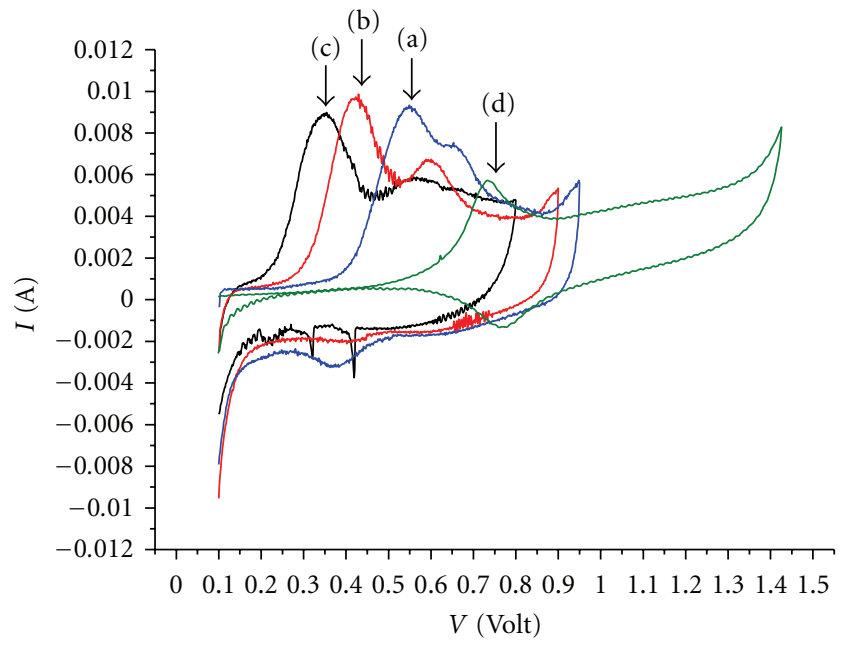
(a) $25^{\circ} \mathrm{C}$
(c) $80^{\circ} \mathrm{C}$
(b) $60^{\circ} \mathrm{C}$
(d) $60^{\circ} \mathrm{C}$

FIgURE 14: The striping voltammograms for CO desorption from supported $10 \mathrm{wt} . \%\left(0.4 \mathrm{mg} \mathrm{cm}^{-2}, 2 \mathrm{~nm}\right.$ in average size, $1: 1$ atomic ratio $\mathrm{Ru}: \mathrm{Pt}) \mathrm{RuPt} / \mathrm{TiO}_{2} / \mathrm{C}$ electrocatalyst $\mathrm{CO}$-saturated at three different temperatures: 25 (a), 60 (b), and 80 (c) ${ }^{\circ} \mathrm{C}$, scanned at the scan rate of $2 \mathrm{mV} \mathrm{s}^{-1}$; (d) the same stripping scans for $\mathrm{CO}$ desorption at $60^{\circ} \mathrm{C}$ from unsupported $30 \mathrm{wt} . \%\left(0.5 \mathrm{mg} \mathrm{cm}^{-2}\right.$, same average nanosize) E-tek $\mathrm{RuPt} / \mathrm{C}$ electrocatalyst of the same $\mathrm{RuPt}$ nanosize, atomic ratio and load, sweep rate $10 \mathrm{mV} \cdot \mathrm{s}^{-1}$, and its $\mathrm{CO}$ saturation at $55^{\circ} \mathrm{C}$

same effect for more than $300 \mathrm{mV}$ relative to $\mathrm{RuPt} / \mathrm{C}$ catalyst (Figure 14). Anodic $\mathrm{CO}$ oxidation upon $\mathrm{Ru}, \mathrm{Pt} / \mathrm{TiO}_{2} / \mathrm{C}$ starts even within the potential range of UPD desorption of $\mathrm{H}$ adatoms and becomes much more pronounced in the charge

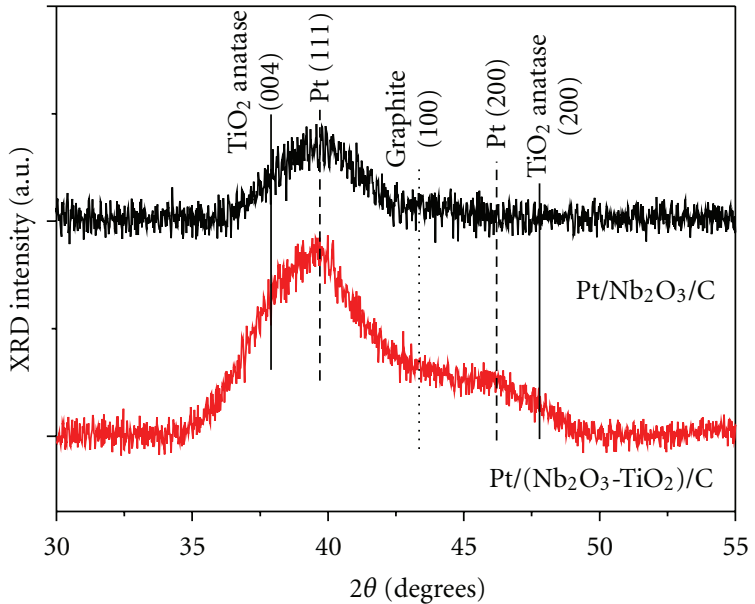

Figure 15: XRD spectra of the Pt supported on $\mathrm{Nb}_{2} \mathrm{O}_{3} / \mathrm{C}$ and $\left(\mathrm{Nb}_{2} \mathrm{O}_{3}-\mathrm{TiO}_{2}\right) / \mathrm{C}$. The lines drown in the figure show the positions of the respective reflections.

capacity relative to $\mathrm{Ru}, \mathrm{Pt} / \mathrm{C}$. This important result is one of the most significant confirmations of the present interactive and dynamic spillover catalytic model, as implemented in electrocatalysis for hydrogen and oxygen electrode reactions. In such a context, Figure 3 illustrates the primary role of water (left peaks) versus $\mathrm{M}-\mathrm{OH}$ (right peaks) by DRIFT relevance, as the a priori initial source of primary oxides and supports the just revealed spillover effect and evidence.

It should also be inferred that mixed anatase (and even rutile) titania and, in particular, tungstenia form intermolecular solid oxide solutions of a high altervalent 

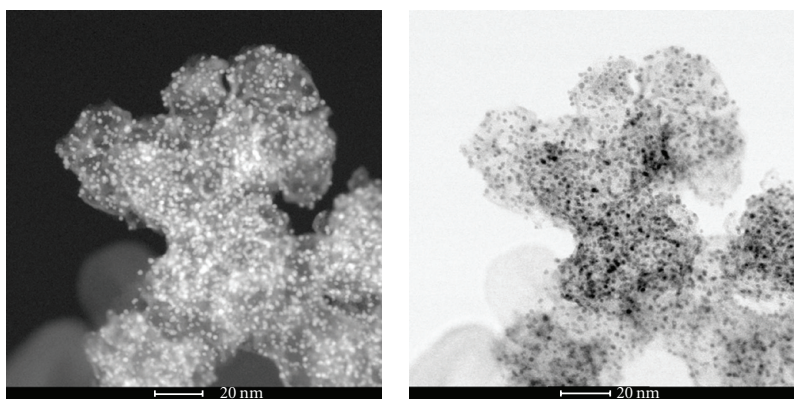

(a)
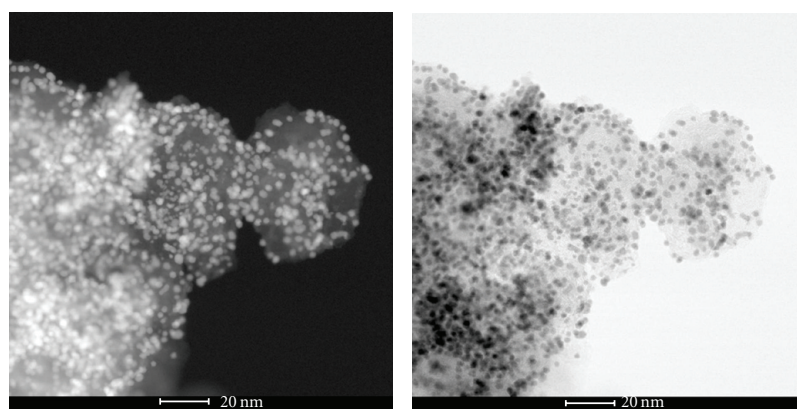

(c)
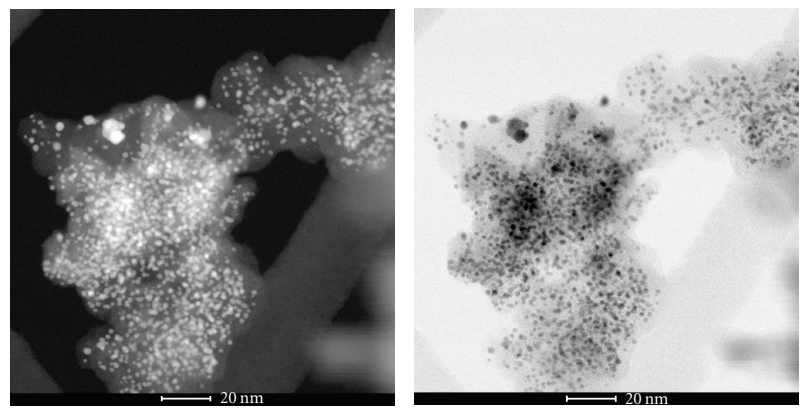

(b)
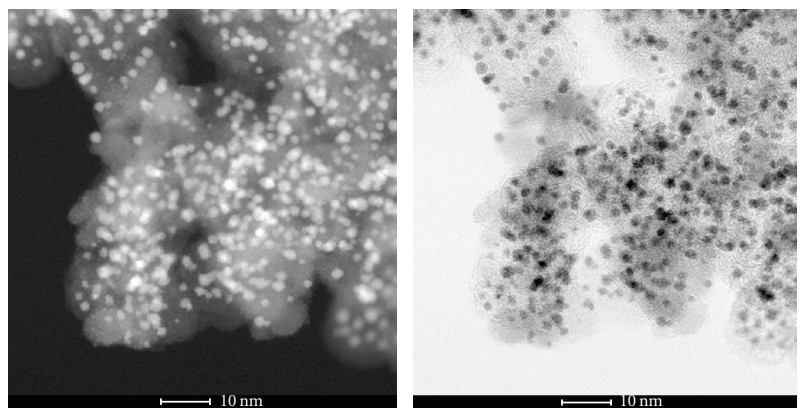

(d)

FIGURE 16: Scanning transmission electron nanoimages of TM hypo-d-oxide/carbon support material and nanostructured Pt electrocatalyst nanoparticles: (i) High-resolution high-angle annular dark-field scanning transmission electron micrograph or Z-contrast nanographs (lefthand order) and (ii) Bright-field nanoimages of somewhat higher resolution, but missing the smallest nanoparticles (right-hand order). Labels: (a) Composite simple basic Nb-oxide interactive (SMSI) supported electrocatalyst, $\left\{\mathrm{Pt}(10 \mathrm{wt} . \%) / 20 \mathrm{wt} . \% \mathrm{Nb}_{2} \mathrm{O}_{5} / \mathrm{C}\right\}$; (b) Congenial altervalent supported electrocatalyst, $\left\{\mathrm{Pt}(10 \mathrm{wt} . \%) / 20 \mathrm{wt} . \% \mathrm{Nb}_{2} \mathrm{O}_{5}, \mathrm{TiO}_{2} / \mathrm{C}\right\}$; (c) Composite interactive (SMSI) altervalent supported electrocatalyst of the same hypo-d-oxide structure as in (b), but of triple higher Pt weight percentage, $\left\{\mathrm{Pt}(30 \mathrm{wt} . \%) / 20 \mathrm{wt} . \% \mathrm{Nb}_{2} \mathrm{O}_{5}\right.$, $\left.\mathrm{TiO}_{2} / \mathrm{C}\right\}$, and (d) congenial altervalent supported electrocatalyst as in (b), but based on mixed W-oxide and anatase titania interactive supported Pt clusters. Courtesy of F. Nan and Professor Gianluigi Botton (McMaster University) for nanoimages.

capacity (Scheme 2, [1]), compatible both in amorphous and crystalline forms of the edge sharing $\mathrm{TiO}_{6}$ and the corner sharing $\mathrm{WO}_{6}$ octahedrons, with pronouncedly increased electrochromic features even at high contents of the former $[84,85]$. In fact, highly charged $\mathrm{W}^{6+}$ cations, like $\mathrm{Nb}^{5+}$, additionally favor the reversible acidic dissociation of water molecules [15, 16, 57], and, thereby, such electrochromic layers exhibit well defined ion exchange and electron conductive properties [2, 3, 15-19, 57]. Thus, one of the fundamental contributions of the present paper is to show that prevailing anatase titania in the form of a composite catalytic support with tungstenia (and/or niobia, tantalia, and even molybdenia), which is stable for alkaline media too, also behaves in a compatible way and, regarding the $\left(\mathrm{Pt} / \mathrm{H}_{0.35} \mathrm{WO}_{3} \Leftrightarrow \mathrm{Pt} / \mathrm{W}(\mathrm{OH})_{6}\right)$ reversibility, features the same properties as pure tungsten bronze itself!

\subsection{XRD and UHRTEM Nanostructured Characterization of} Hypo-d-oxide-Supported Electrocatalysts. The spectrum for the $\mathrm{Pt} /\left(\mathrm{Nb}_{2} \mathrm{O}_{3}-\mathrm{TiO}_{2}\right) / \mathrm{C}$ catalyst shows an overlapped region between 35 and 50 degrees (Figure 15). In this region one expects the reflection lines for the $\mathrm{Pt}(111)$ and (200), $\mathrm{TiO}_{2}$ anatase (004) and (200) and as well as the graphitic (100) crystallographic planes, shown with the labeling straight lines drawn therein. Evidently, all the above mentioned reflections are essentially overlapped. In this respect, it is not possible to estimate exactly the $\mathrm{Pt}$ and $\mathrm{TiO}_{2}$ particle size, while peaks attributable to $\mathrm{Nb}$ specimens are at the noise level and absent, due to their very small amount. $\mathrm{Nb}$ oxide reflection peaks are also absent from the XRD spectrum of the $\mathrm{Pt} / \mathrm{Nb}_{2} \mathrm{O}_{3} / \mathrm{C}$ catalyst, though the amount of niobia is now significantly higher as compared to the $\mathrm{Pt} /\left(\mathrm{Nb}_{2} \mathrm{O}_{3}-\mathrm{TiO}_{2}\right) / \mathrm{C}$ sample. The only visible reflection peak in the $\mathrm{Pt} / \mathrm{Nb}_{2} \mathrm{O}_{3} / \mathrm{C}$ sample is ascribed to the $\mathrm{Pt}$ (111) crystallographic plane. By fitting this particular peak with a Gaussian function, it is possible to estimate the average Pt particle size by applying the Scherrer equation. It was found to be approximately $2.2 \mathrm{~nm}$, this way indicating the highly and uniformly dispersed nature of such a catalyst. From $\mathrm{H}_{2}$ chemisorption measurements [39], the average Pt particle size was estimated to be $3.7 \mathrm{~nm}\left(77 \mathrm{~m}^{2} / \mathrm{gr}\right.$ of Pt assuming spherical particles, while the electrochemically active surface area, UPD $\mathrm{H}$-adatoms estimated by the corresponding potentiodynamic desorption peaks, is even lower, $57.5 \mathrm{~m}^{2} / \mathrm{gr}$ of $\mathrm{Pt}$ ). The significantly larger Pt particles estimated by the $\mathrm{H}_{2}$ chemisorption indicate the interaction between the Pt particles and the oxide support that hinders the $\mathrm{H}_{2}$ adsorptive properties of $\mathrm{Pt}$ crystallites, leading to particle size overestimation. On the other hand, the particle 
size determination by XRD is usually overestimated (the overlapping effect), and, since the size is close to the instrument limits, such a state of experimental evidence convincingly suggests that Pt particles are evenly dispersed and strongly bonded on the hypo-d-oxide catalytic support as shown by many XRD measurements with similar interactive hypo-d-oxide supported electrocatalysts. The absence of niobia reflection peaks indicates that $\mathrm{Nb}$ oxides are either highly sub- to monolayer dispersed on the carbon particle surface (as essentially the surface species) or less probably in amorphous state. In fact, the present electrocatalyst has been $a$ priori planned and calculated by the mass and surface ratio between hypo-d-oxide and Vulcan carbon particles to be deposited as submonolayer $\left(\mathrm{Nb}_{2} \mathrm{O}_{5}\right.$ having $170 \mathrm{~m}^{2} \mathrm{~g}^{-1}$, while carbon particles being in higher amount and of much larger surface area, $260 \mathrm{~m}^{2} \mathrm{~g}^{-1}$ ). Such a unique XRD experimental insight convincingly testifies to the existence of high Pt (111) bronze dispersion upon highly developed hypo-d-oxide support. Such a state relative to the standard $\mathrm{Pt} / \mathrm{C}$ electrocatalyst, otherwise suffering from agglomeration, characterizes remarkably increased electrocatalytic activity, a much longer-lasting catalyst because of the SMSI bonding effect, while the interactive structure enables Pt metal recovery, which is another high-quality achievement of the novel nanostructured bronze-type electrocatalysts. Meanwhile, the most significant is the control of homogeneous dispersion of grafted nanostructured Pt size magnitude: the ratio of available exposed hypo-d-oxide surface relative to the $\mathrm{Pt}$ wt.\% defines the latter, and in our issues it is usually fixed between 2.0 and $2.4 \mathrm{~nm}$ in average, in particular for Nb-O-, $\mathrm{W}-\mathrm{O}-$, and Ti-O- individual and mixed-valence composite hypo-d-supports (SMSI), for Ta-O- not yet optimized. However, UHRTEM $(0.7 \mathrm{~nm}$ resolution) identifies plenty of about $1.0 \mathrm{~nm}$ Pt clusters.

The UHRTEM (ultrahigh resolution transmission electron microscopy, FEI Titan 80-300 cubed, equipped with two aberration correctors (CEOS) and a high-brightness source) nanoimages reveal the strong interactive grafted Pt nanoclusters on hypo-d-oxides supports, with a rather uniform and evenly homogeneous distribution in average of about 2 to $2.5 \mathrm{~nm}$ in nanosize on the best issues $\left\{\mathrm{Pt}(10 \mathrm{wt} . \%) / 20 \mathrm{wt} . \% \mathrm{Nb}_{2} \mathrm{O}_{5}, \mathrm{TiO}_{2} / \mathrm{C}\right\}$, Figure $16(\mathrm{~b})$, $\left\{\mathrm{Pt}(10 \mathrm{wt} . \%) / 20 \mathrm{wt} . \% \mathrm{Nb}_{2} \mathrm{O}_{5} / \mathrm{C}\right\}$, Figure $16(\mathrm{a})$, and $\{\mathrm{Pt}$ (10 wt.\%)/20 wt.\% $\left.\mathrm{WO}_{3}, \mathrm{TiO}_{2} / \mathrm{C}\right\}$, Figure 16(d), obtained so far and already confirmed by XRD scans (resolution $0.7 \mathrm{~nm}$ ). Even more so, with triple larger $\mathrm{Pt}$ amount $\left\{\mathrm{Pt}(30\right.$ wt. $\%) / 20$ wt. $\left.\% \mathrm{Nb}_{2} \mathrm{O}_{5}, \mathrm{TiO}_{2} / \mathrm{C}\right\}$, Figure 16(c), the homogeneous nanostructured $\mathrm{Pt}$ distribution keeps the same trend and in particular the average nanosize. Such a homogeneous nanosize level of distribution has never so far been achieved and confirms the basis for the rather pronounced spillover effect and the unique electrocatalytic achievements. No single Pt nanostructured cluster has been noticed on the prevailing carbon nanoparticles percentage of their otherwise highly developed exposed surface area and no agglomeration. It would certainly be worthwhile noticing a rather allover homogeneous widespreading of the interactive hypo-d-oxide support structure and well distinct inter-dd-bonded and interactive (SMSI) grafted fine Pt nanosized clusters upon them, as a unique nanostructured Pt-bronze substantiation of advanced electrocatalytic properties, primarily and mostly extended by the pronounced spillover effect.

\section{Conclusions}

The present paper has shown that, beside the SMSI effect, the interactive grafted and supported hyper-d-elements and their composites, without exception, feature the reversible and thereby fast spillover phenomena both for $\mathrm{H}$-adatoms during the cathodic and the primary oxide $(\mathrm{M}-\mathrm{OH})$ in the course of anodic polarization, as an additional dynamic catalytic effect in conjunction with the hypo-hyper-d-dinterelectronic bonding contribution to the overall synergistic electrocatalytic activity. Nanostructured reversibly interchangeable $\left(\mathrm{Pt} / \mathrm{H}_{0.35} \mathrm{WO}_{3} \Leftrightarrow \mathrm{Pt} / \mathrm{W}(\mathrm{OH})_{6}\right)$ alterpolar bronzetype and its $\mathrm{TiO}_{2}$-modified mixed-valence compound-type $\left(\mathrm{Pt} / \mathrm{Nb}_{2} \mathrm{O}_{5}, \mathrm{TiO}_{2} / \mathrm{C}, \mathrm{Pt} / \mathrm{WO}_{3}, \mathrm{TiO}_{2} / \mathrm{C}\right)$ electrocatalyst issues for hydrogen and primarily oxygen electrode reactions (HER, HOR, ORR, OER) have for the first time been developed and produced by a proper sol-gel synthetic method and comprise unpredictable unique advantages in electrocatalysis. Since these four electrode reactions are instantaneously and reversibly interchangeable on the same electrocatalyst (bronze and hydrated state) properties and feature substantially pronounced individual reversible properties for each of them, several significant achievements resulted therein.

(i) XPS, DRIFT, FTIR, and potentiodynamic spectra have been employed to show the a priori existence of the primary oxide species, as predestined for spillover by the membrane transfer through the interactive (SMSI) bonded hypo-d-oxide supports and being available for the double layer charging and discharging. XPS analysis has also confirmed the membrane mechanism in $\mathrm{Pt}-\mathrm{OH}$ transference and spillover (confirmed surface $\mathrm{Ti}^{3+}$ versus $\mathrm{Nb}^{5+}$ in the ratio $1: 1$ ), as well as the estimated SMSI bonding effect at the $\mathrm{Au} / \mathrm{TiO}_{2}$ interphase, and indicated the existence of the intermetallic phase $\left(\mathrm{TiPt}_{3}\right.$ at $\mathrm{Pt} / \mathrm{TiO}_{2}$ interface) that enables the entire interactive catalytic synergistic activity. In similar respect, XRD scans in conjunction with UHRTEM contributed to further supportive conclusions concerning the particle size and homogeneous distribution of the metallic phase of such composite electrocatalysts and the interionic interference between titania and niobia, tungstenia, or tantalia. In addition, potentiodynamic spectra scanned under wet and dry PEM proved the whole spillover phenomena of primary oxide and its UPD and OPD double layer charging and discharging, as well as the interchangeable alternating $\mathrm{H}$-adatoms effusion. Cyclic voltammetry in admixture of formaldehyde is cited to reinforce such phenomenological statements, while Ertel ${ }^{57}$ auto- or self-catalytic effect of water molecules, particularly within the double layer structure, was added to 
complete the overall phenomenon of effusion and its nature and properties.

(ii) Since interactive (SMSI) d-d bonded on suitable hypo-d-oxide supports, $\mathrm{Pt}$ nanoparticles are first properly grafted upon them, uniformly distributed, and evenly dispersed at the optimal nanosize. The corresponding supported Pt nanoclusters are thereby prevented from agglomeration, thence provide longer lasting of the electrocatalytic activity and even afford possibilities for Pt recovery, otherwise so far missing in LT PEMFC operation and uses.

(iii) Such reversibly alterpolar and multifunctional electrocatalyst composite enables a still expensive, but functionally, technologically, and catalytically ideal, revertible cell system between PEMFC and WE and opens the way towards cheaper ones. In other words, a proper alkaline membrane might enable the use of the same interchangeable doubled spillover of $\mathrm{M}-\mathrm{OH}$ and $\mathrm{H}$-adatoms species in a rather mild environment upon nonnoble interactive hypo-d-oxide-supported electrocatalysts, as the main promising system for mobile PEMFC.

(iv) All proper combinations between higher altervalent capacity hypo-d-oxides $\left(\mathrm{Nb}_{2} \mathrm{O}_{5}, \mathrm{WO}_{3}, \mathrm{TaO}_{2}\right)$ and anatase $\mathrm{TiO}_{2}$, thermally produced, feature high electron conductivity and enable us to avoid the nanosized carbon current collector and as a catalyst support in PEMFC and WE, which is decisive for anodic oxygen evolution.

(v) Electrocatalytic activity for the ORR has been advanced for more than an order of magnitude [1] relative to the standard nanostructured $\mathrm{Pt} / \mathrm{C}$ electrocatalyst, enabling us to reduce Pt load for more than four times in L\&MT PEMFC and still keep the same activity.

(vi) The present and former experimental evidence [14] have shown that, within the reversible part of Tafel plot, in particular hypo-d-oxide supported Pt electrocatalysts are always partially covered by its oxides, and thereby polarization for the ORR starts at more positive potential values and, consequently, increasingly acquiring the reversible oxygen electrode properties [1-4]. Thus, one of the conclusions is that the present paper has shown the way towards the reversible oxygen electrode, as one of the main goals in aqueous electrochemistry, at least for the ORR.

\section{Acknowledgments}

The present study has been the result of several EU research projects (acronyms Apollon, Prometheas) and mostly carried out in the ICEHT/FORTH Laboratories in Patras, Greece, ones of the European leading both in L\&MT PEMFC and in particular in electrocatalysis; all authors feel the recognition and gratitudes to their institute.

\section{References}

[1] J. M. Jaksic, D. Labou, G. D. Papakonstantinou, A. Siokou, and M. M. Jaksic, "Novel spillover interrelating reversible electrocatalysts for oxygen and hydrogen electrode reactions," Journal of Physical Chemistry C, vol. 114, no. 43, pp. 1829818312, 2010.

[2] J. M. Jaksic, N. V. Krstajic, L. M. Vracar et al., "Spillover of primary oxides as a dynamic catalytic effect of interactive hypo-d-oxide supports," Electrochimica Acta, vol. 53, no. 2, pp. 349-361, 2007.

[3] N. V. Krstajic, L. M. Vracar, V. R. Radmilovic et al., "Advances in interactive supported electrocatalysts for hydrogen and oxygen electrode reactions," Surface Science, vol. 601, no. 9, pp. 1949-1966, 2007.

[4] J. M. Jaksic, D. Labou, C. M. Lacnjevac, A. Siokou, and M. M. Jaksic, "Potentiodynamic estimation of key parametric criterions and interrelating reversible spillover effects for electrochemical promotion," Applied Catalysis A, vol. 380, no. 1-2, pp. 1-14, 2010.

[5] C. M. Guldberg and P. Waage, "Concerning chemical affinity," Erdmann's Journal für Practische Chemie, vol. 127, pp. 69-114, 1979.

[6] E. W. Lund, "Guldberg and waage and the law of mass action," Journal of Chemical Education, vol. 42, no. 10, pp. 548-550, 1965.

[7] M. Boudart, M. A. Vannice, and J. E. Benson, "Adlineation, portholes and spillover," Zeitschrift für Physikalische Chemie, vol. 64, no. 1-4, pp. 171-177, 1969.

[8] H. W. Kohn and M. Boudart, "Reaction of hydrogen with oxygen adsorbed on a platinum catalyst," Science, vol. 145, no. 3628, pp. 149-150, 1964.

[9] J. E. Benson, H. W. Kohn, and M. Boudart, "On the reduction of tungsten trioxide accelerated by platinum and water," Journal of Catalysis, vol. 5, no. 2, pp. 307-313, 1966.

[10] M. A. Vannice, M. Boudart, and J. J. Fripiat, "Mobility of hydrogen in hydrogen tungsten bronze," Journal of Catalysis, vol. 17, no. 3, pp. 359-365, 1970.

[11] A. D. Lueking and R. T. Yang, "Hydrogen spillover to enhance hydrogen storage-study of the effect of carbon physicochemical properties," Applied Catalysis A, vol. 265, no. 2, pp. 259-268, 2004.

[12] J. G. Kim and J. R. Regalbuto, "The effect of calcination on $\mathrm{H} 2$ spillover in $\mathrm{Pt} / \mathrm{MoO}_{3}$. II. Kinetic modeling," Journal of Catalysis, vol. 139, no. 1, pp. 175-190, 1993.

[13] R. K. Agarwal, J. S. Noh, J. A. Schwarz, and P. Davini, "Effect of surface acidity of activated carbon on hydrogen storage," Carbon, vol. 25, no. 2, pp. 219-226, 1987.

[14] H. Takagi, H. Hatori, and Y. Yamada, "Reversible adsorption/desorption property of hydrogen on carbon surface," Carbon, vol. 43, no. 14, pp. 3037-3039, 2005.

[15] A. Vittadini, A. Selloni, F. P. Rotzinger, and M. Grätzel, "Structure and energetics of water adsorbed at $\mathrm{TiO}_{2}$ anatase (101) and (001) surfaces," Physical Review Letters, vol. 81, no. 14 , pp. 2954-2957, 1998.

[16] A. Valdes and G. J. Kroes, "First principles study of the photooxidation of water on tungsten trioxide (WO3)," Journal of Chemical Physics, vol. 130, no. 11, Article ID 114701, 2009.

[17] J. Livage, M. Henry, and C. Sanchez, "Sol-gel chemistry of transition metal oxides," Progress in Solid State Chemistry, vol. 18, no. 4, pp. 259-341, 1988.

[18] P. Judeinstein and J. Livage, "Sol-gel synthesis of WO3 thin films," Journal of Materials Chemistry, vol. 1, no. 4, pp. 621627, 1991. 
[19] J. Livage and G. Guzman, "Aqueous precursors for electrochromic tungsten oxide hydrates," Solid State Ionics, vol. 84, no. 3-4, pp. 205-211, 1996.

[20] S. G. Neophytides, S. H. Zafeiratos, and M. M. Jaksic, "Selective interactive grafting of composite bifunctional electrocatalysts for simultaneous anodic hydrogen and Co oxidation: I. Concepts and embodiment of novel-type composite catalysts," Journal of the Electrochemical Society, vol. 150, no. 10, pp. E512-E526, 2003.

[21] S. G. Neophytides, K. Murase, S. Zafeiratos et al., "Composite hypo-hyper-d-intermetallic and interionic phases as supported interactive electrocatalysts," Journal of Physical Chemistry B, vol. 110, no. 7, pp. 3030-3042, 2006.

[22] S. J. Tauster and S. C. Fung, "Strong metal-support interactions: occurrence among the binary oxides of groups IIA-VB," Journal of Catalysis, vol. 55, no. 1, pp. 29-35, 1978.

[23] S. J. Tauster, S. C. Fung, R. T. K. Baker, and J. A. Horsley, "Strong interactions in supported-metal catalysts," Science, vol. 211, no. 4487, pp. 1121-1125, 1981.

[24] S. A. Stevenson, Metal-Support Interaction in Catalysis, Sintering and Redispersion, D. Van Nostrand, New York, NY, USA, 1987.

[25] G. L. Haller and D. E. Resasco, "Metal-support interaction: group VIII metals and reducible oxides," Advances in Catalysis, vol. 36, pp. 173-235, 1989.

[26] P. Panagiotopoulou and D. I. Kondarides, "Effect of the nature of the support on the catalytic performance of noble metal catalysts for the water-gas shift reaction," Catalysis Today, vol. 112, no. 1-4, pp. 49-52, 2006.

[27] P. Panagiotopoulou and D. I. Kondarides, "A comparative study of the water-gas shift activity of Pt catalysts supported on single $\left(\mathrm{MO}_{x}\right)$ and composite $\left(\mathrm{MO}_{x} / \mathrm{Al}_{2} \mathrm{O}_{3}, \mathrm{MO}_{x} / \mathrm{TiO}_{2}\right)$ metal oxide carriers," Catalysis Today, vol. 127, no. 1-4, pp. 319-329, 2007.

[28] C. Kokkofitis, G. Karagiannakis, and M. Stoukides, "Study of the water gas shift reaction on Fe in a high temperature proton conducting cell," Catalysis Today, vol. 127, no. 1-4, pp. 330336, 2007.

[29] M. Daté and M. Haruta, "Moisture effect on CO oxidation over $\mathrm{Au} / \mathrm{TiO}_{2}$ catalyst," Journal of Catalysis, vol. 201, no. 2, pp. 221-224, 2001.

[30] S. Völkening, K. Bedürftig, K. Jacobi, J. Wintterlin, and G. Ertl, "Dual-path mechanism for catalytic oxidation of hydrogen on platinum surfaces," Physical Review Letters, vol. 83, no. 13, pp. 2672-2675, 1999.

[31] M. T. M. Koper and R. A. Van Santen, "Interaction of H, $\mathrm{O}$ and $\mathrm{OH}$ with metal surfaces," Journal of Electroanalytical Chemistry, vol. 472, no. 2, pp. 126-136, 1999.

[32] H. Angerstein-Kozlowska, B. E. Conway, and W. B. A. Sharp, "The real condition of electrochemically oxidized platinum surfaces. Part I. Resolution of component processes," Journal of Electroanalytical Chemistry, vol. 43, no. 1, pp. 9-36, 1973.

[33] H. Angerstein-Kozlowska, B. E. Conway, A. Hamelin, and L. Stoicoviciu, "Elementary steps of electrochemical oxidation of single-crystal planes of Au-I. Chemical basis of processes involving geometry of anions and the electrode surfaces," Electrochimica Acta, vol. 31, no. 8, pp. 1051-1061, 1986.

[34] H. Angerstein-Kozlowska, B. E. Conway, A. Hamelin, and L. Stoicoviciu, "Elementary steps of electrochemical oxidation of single-crystal planes of $\mathrm{Au}$ Part II. A chemical and structural basis of oxidation of the (111) plane," Journal of Electroanalytical Chemistry, vol. 228, no. 1-2, pp. 429-453, 1987.
[35] H. Angerstein-Kozlowska, B. E. Conway, K. Tellefsen, and B. Barnett, "Stochastically-gated surface processes involving anions in oxidation of Au: time-resolution of processes down to $0.25 \%$ coverages and $50 \mu$ s time-scales," Electrochimica Acta, vol. 34, no. 8, pp. 1045-1056, 1989.

[36] B. E. Conway, B. Barnett, H. Angerstein-Kozlowska, and B. V. Tilak, "A surface-electrochemical basis for the direct logarithmic growth law for initial stages of extension of anodic oxide films formed at noble metals," The Journal of Chemical Physics, vol. 93, no. 11, pp. 8361-8373, 1990.

[37] B. E. Conway, "Electrochemical oxide film formation at noble metals as a surface-chemical process," Progress in Surface Science, vol. 49, no. 4, pp. 331-452, 1995.

[38] N. M. Ristic, M. Kotorcevic, C. M. Lacnjevac, A. M. Jokic, and M. M. Jaksic, "Some specific potentiodynamic behaviour of certain aldehydes and monosaccharides: some simple and some specific aldehydes," Electrochimica Acta, vol. 45, no. 18, pp. 2973-2989, 2000.

[39] S. Zafeiratos, G. Papakonstantinou, M. M. Jacksic, and S. G. Neophytides, "The effect of Mo oxides and $\mathrm{TiO}_{2}$ support on the chemisorption features of linearly adsorbed CO on Pt crystallites: an infrared and photoelectron spectroscopy study," Journal of Catalysis, vol. 232, no. 1, pp. 127-136, 2005.

[40] J. M. Jaksic, L. Vracar, S. G. Neophytides et al., "Structural effects on kinetic properties for hydrogen electrode reactions and CO tolerance along Mo-Pt phase diagram," Surface Science, vol. 598, no. 1-3, pp. 156-173, 2005.

[41] M. Suh, P. S. Bagus, S. Pak, M. P. Rosynek, and J. H. Lunsford, "Reactions of hydroxyl radicals on titania, silica, alumina, and gold surfaces," Journal of Physical Chemistry B, vol. 104, no. 12, pp. 2736-2742, 2000.

[42] N. D. Lang, "Theory of single-atom imaging in the scanning tunneling microscope," Comments on Condensed Matter Physics, vol. 14, no. 5, pp. 253-257, 1989.

[43] D. Y. Zemlyanov, E. Savinova, A. Scheybal, K. Doblhofer, and R. Schlögl, "XPS observation of OH groups incorporated in an Ag(111) electrode," Surface Science, vol. 418, no. 2, pp. 441456, 1998.

[44] B. Hammer and J. K. Norskov, "Theoretical surface science and catalysis-calculations and concepts," Advances in Catalysis, vol. 45, pp. 71-129, 2000.

[45] G. Nguyen van Huong, C. Hinnen, and J. Lecoeur, "Spectroscopic investigation of single crystal gold electrodes. Part II. The incipient oxidation of gold electrode," Journal of Electroanalytical Chemistry, vol. 106, pp. 185-191, 1980.

[46] J. F. Weaver and G. B. Hoflund, "Surface characterization study of the thermal decomposition of AgO," Journal of Physical Chemistry, vol. 98, no. 34, pp. 8519-8524, 1994.

[47] M. Mavrikakis, P. Stoltze, and J. K. Norskov, "Making gold less noble," Catalysis Letters, vol. 64, no. 2-4, pp. 101-106, 2000.

[48] A. C. C. Tseung, P. K. Shen, and K. Y. Chen, "Precious metal/hydrogen bronze anode catalysts for the oxidation of small organic molecules and impure hydrogen," Journal of Power Sources, vol. 61, no. 1-2, pp. 223-225, 1996.

[49] A. C. C. Tseung and K. Y. Chen, "Hydrogen spill-over effect on $\mathrm{Pt} / \mathrm{WO}_{3}$ anode catalysts," Catalysis Today, vol. 38, no. 4, pp. 439-443, 1997.

[50] P. K. Shen, K. Y. Chen, and A. C. C. Tseung, "Performance of CO-electrodeposited Pt-Ru/ $\mathrm{WO}_{3}$ electrodes for the electrooxidation of formic acid at room temperature," Journal of Electroanalytical Chemistry, vol. 389, no. 1-2, pp. 223-225, 1995.

[51] O. Glemser and K. Naumann, "Kristallisierte wolframblauverbindungen; wasserstoffanaloga der wolframbronzen 
HxWO3," Zeitschrift für Anorganische Chemie, vol. 365, no. 46, pp. 288-302, 1951.

[52] M. M. Jaksic, "Advances in electrocatalysis for hydrogen evolution in the light of the Brewer-Engel valence-bond theory," Journal of Molecular Catalysis, vol. 38, no. 1-2, pp. 161-202, 1986.

[53] L. Brewer, "Bonding and structures of transition metals," Science, vol. 161, no. 3837, pp. 115-122, 1968.

[54] J. Friedel and C. M. Sayers, "On the role of d-d-electron correlations in the cohesion and ferromagnetism of transition metals," Journal de Physique, vol. 38, pp. 697-705, 1977.

[55] S. G. Neophytides, S. Zafeiratos, G. D. Papakonstantinou, J. M. Jaksic, F. E. Paloukis, and M. M. Jaksic, "Extended Brewer hypo-hyper-d-interionic bonding theory II. Strong metalsupport interaction grafting of composite electrocatalysts," International Journal of Hydrogen Energy, vol. 30, no. 4, pp. 393-410, 2005.

[56] S. G. Neophytides, S. Zafeiratos, G. D. Papakonstantinou, J. M. Jaksic, F. E. Paloukis, and M. M. Jaksic, "Extended Brewer hypo-hyper-d-interionic bonding theory-I. Theoretical considerations and examples for its experimental confirmation," International Journal of Hydrogen Energy, vol. 30, no. 2, pp. 131-147, 2005.

[57] A. Tilocca and A. Selloni, "Reaction pathway and free energy barrier for defect-induced water dissociation on the (101) surface of $\mathrm{TiO}_{2}$-anatase," Journal of Chemical Physics, vol. 119, no. 14, pp. 7445-7450, 2003.

[58] J. Greeley and M. Mavrikakis, "Alloy catalysts designed from first principles," Nature Materials, vol. 3, no. 11, pp. 810-815, 2004.

[59] M. M. Jaksic, "Hypo-hyper-d-electronic interactive nature of synergism in catalysis and electrocatalysis for hydrogen reactions," Electrochimica Acta, vol. 45, no. 25-26, pp. 40854099, 2000.

[60] T. J. Schmidt, H. A. Gasteiger, G. D. Stäb, P. M. Urban, D. M. Kolb, and R. J. Behm, "Characterization of high-surface-area electrocatalysts using a rotating disk electrode configuration," Journal of the Electrochemical Society, vol. 145, no. 7, pp. 23542358, 1998.

[61] X. Zhang, K. Y. Chan, and A. C. C. Tseung, "Electrochemical oxidation of glucose by $\mathrm{Pt} \mathrm{WO}_{3}$ electrode," Journal of Electroanalytical Chemistry, vol. 386, no. 1-2, pp. 241-243, 1995.

[62] M. Peuckert, F. P. Coenen, and H. P. Bonzel, "XPS study of the electrochemical surface oxidation of Platinum in $\mathrm{N} \mathrm{H}_{2} \mathrm{SO}_{4}$ acid electrolyte," Electrochimica Acta, vol. 29, no. 10, pp. 13051314, 1984.

[63] J. E. Drawdy, G. B. Hoflund, S. D. Gardner, E. Yngvadottir, and D. R. Schryer, "Effect of pretreatment on a platinized tin oxide catalyst used for low-temperature CO oxidation," Surface and Interface Analysis, vol. 16, no. 1-12, pp. 369-374, 1990.

[64] T. Akita, K. Tanaka, S. Tsubota, and M. Haruta, "Analytical high-resolution TEM study of supported gold catalysts: orientation relationship between Au particles and $\mathrm{TiO}_{2}$ supports," Journal of Electron Microscopy, vol. 49, no. 5, pp. 657-662, 2000.

[65] M. Haruta, "Size- and support-dependency in the catalysis of gold," Catalysis Today, vol. 36, no. 1, pp. 153-166, 1997.

[66] F. Boccuzzi, A. Chiorino, S. Tsubota, and M. Haruta, "FTIR study of carbon monoxide oxidation and scrambling at room temperature over gold supported on $\mathrm{ZnO}$ and $\mathrm{TiO}_{2}$. 2," Journal of Physical Chemistry, vol. 100, no. 9, pp. 3625-3631, 1996.

[67] F. Boccuzzi, A. Chiorino, M. Manzoli et al., "Au/ $\mathrm{TiO}_{2}$ nanosized samples: a catalytic, TEM, and FTIR study of the effect of calcination temperature on the CO oxidation," Journal of Catalysis, vol. 202, no. 2, pp. 256-267, 2001.

[68] T. Akita, P. Lu, S. Ichikawa, K. Tanaka, and M. Haruta, Surface and Interface Analysis, vol. 31, pp. 73-113, 2001.

[69] H. Takahashi, I. Harrowfield, C. MacRae, N. Wilson, and K. Tsutsumi, "Analytical TEM study on the dispersion of $\mathrm{Au}$ nanoparticles in $\mathrm{Au} / \mathrm{TiO}_{2}$ catalyst prepared under various temperatures," Surface and Interface Analysis, vol. 31, no. 2, pp. 73-78, 2001.

[70] M. Engelhard, D. Baer, and H. Engelhard, Surface Science Spectra, vol. 71, p. 1, 2000.

[71] M. Engelhard, D. Baer, and H. Engelhard, "Third row transition metals by X-Ray photoelectron spectroscopy," Surface Science Spectra, vol. 7, pp. 1-68, 20030.

[72] R. E. Fuentes, B. L. Garcia, and J. W. Weidner, "A Nb-doped $\mathrm{TiO}_{2}$ electrocatalyst for use in direct methanol fuel cells," ECS Transactions, vol. 12, no. 1, pp. 239-248, 2007.

[73] B. A. Morales, O. Novaro, T. López, E. Sanchez, and R. Gómez, "The effect of hydrolysis catalysts on Ti deficiency and crystallite size of the sol-gelTiO ${ }_{2}$ crystallinephases," Journal of Materials Research, vol. 10, article 2778, 1995.

[74] J. Arbiol, J. Cerdà, G. Dezanneau et al., "Effects of Nb doping on the $\mathrm{TiO}_{2}$ anatase-to-rutile phase transition," Journal of Applied Physics, vol. 92, no. 2, p. 853, 2002.

[75] D. Briggs and M. P. Seah, Eds., Practical Surface Analysis, vol. 1, John Wiley \& Sons, New York, NY, USA, 2nd edition, 1990.

[76] J. A. Martinho Simões and J. L. Beauchamp, "Transition metal-hydrogen and metal-carbon bond strengths: the keys to catalysis," Chemical Reviews, vol. 90, no. 4, pp. 629-688, 1990.

[77] L. C. Anderson, C. E. Mooney, and J. H. Lunsford, "Hydroxyl radical desorption from polycrystalline palladium: evidence for a surface phase transition," Chemical Physics Letters, vol. 196, no. 5, pp. 445-448, 1992.

[78] E. Santos and W. Schmickler, "Electrocatalysis of hydrogen oxidation-theoretical foundations," Angewandte ChemieInternational Edition, vol. 46, no. 43, pp. 8262-8265, 2007.

[79] W. Schmickler, Advanced Physical Chemistry. In press.

[80] B. Hammer and J. K. Norskov, "Why gold is the noblest of all the metals," Nature, vol. 376, no. 6537, pp. 238-240, 1995.

[81] E. Christoffersen, P. Liu, A. Ruban, H. L. Skriver, and J. K. Norskov, "Anode materials for low-temperature fuel cells: a density functional theory study," Journal of Catalysis, vol. 199, no. 1, pp. 123-131, 2001.

[82] M. Watanabe and S. Motoo, "Electrocatalysis by ad-atoms part II. Enhancement of the oxidation of methanol on platinum by ruthenium ad-atoms," Journal of Electroanalytical Chemistry, vol. 60 , no. 3, pp. 267-273, 1975.

[83] J. C. Davies, B. E. Hayden, D. J. Pegg, and M. E. Rendall, "The electro-oxidation of carbon monoxide on ruthenium modified Pt(1 11 1)," Surface Science, vol. 496, no. 1-2, pp. 110 120, 2002.

[84] T. Sonobe, S. Nitta, Y. Katahira et al., "Effect of high frequent vibrating blood flow on the peripheral blood flow distribution using a viblating electro-magnetic pump (VEMP) in the condition of hypoperfusion," Japanese Journal of Artificial Organs, vol. 21, no. 2, pp. 464-471, 1992.

[85] S. Hashimoto and H. Matsuoka, "Lifetime of electrochromism of amorphous $\mathrm{WO}_{3}-\mathrm{TiO}_{2}$ thin films," Journal of the Electrochemical Society, vol. 138, no. 8, pp. 2403-2408, 1991. 


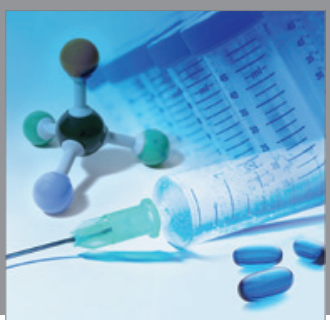

International Journal of

Medicinal Chemistry

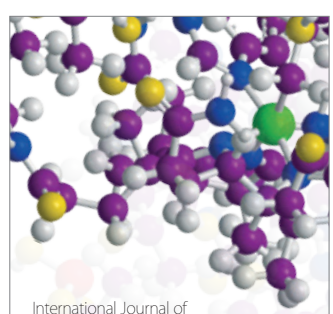

Carbohydrate Chemistry

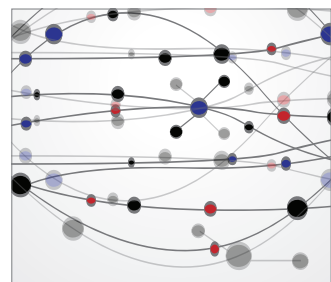

The Scientific World Journal
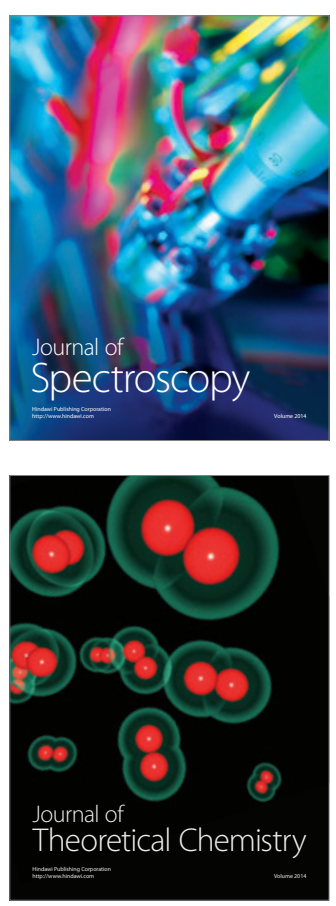
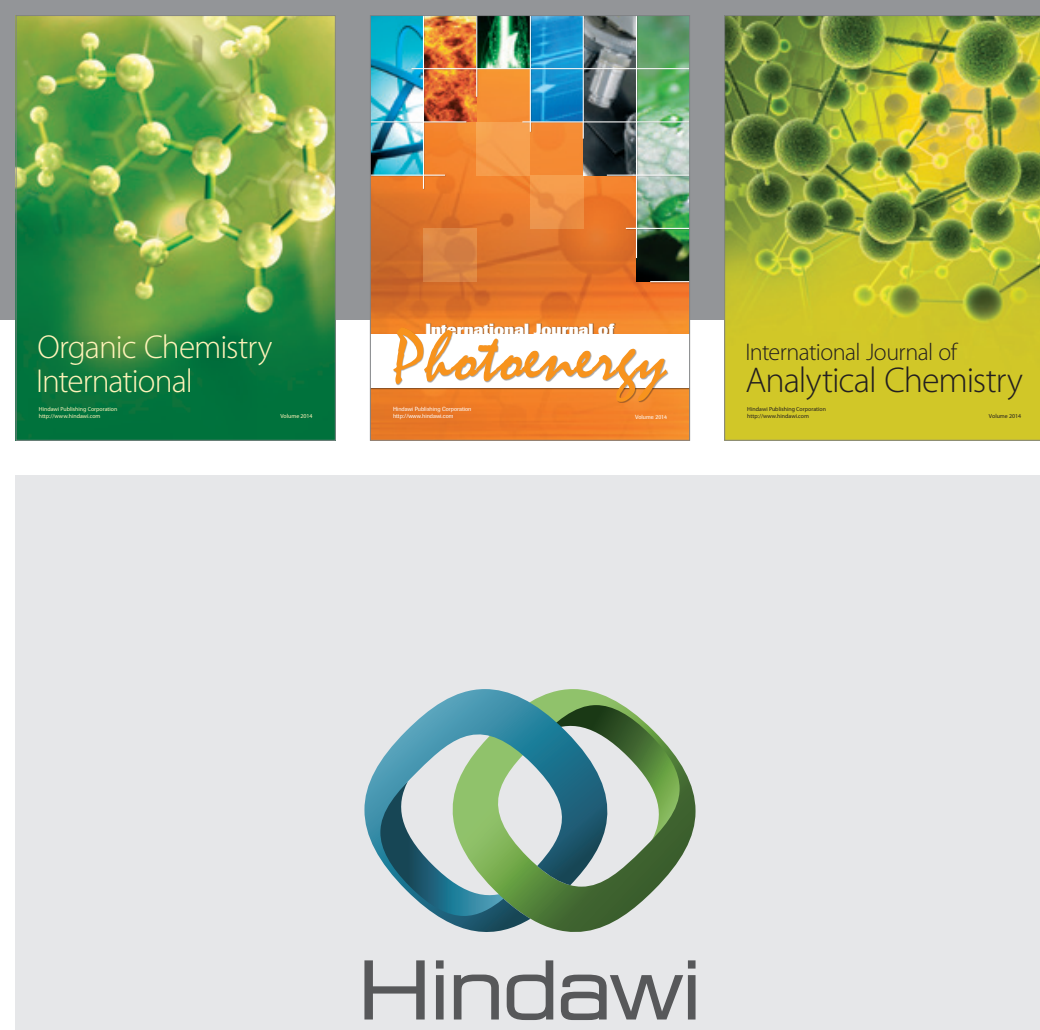

Submit your manuscripts at

http://www.hindawi.com
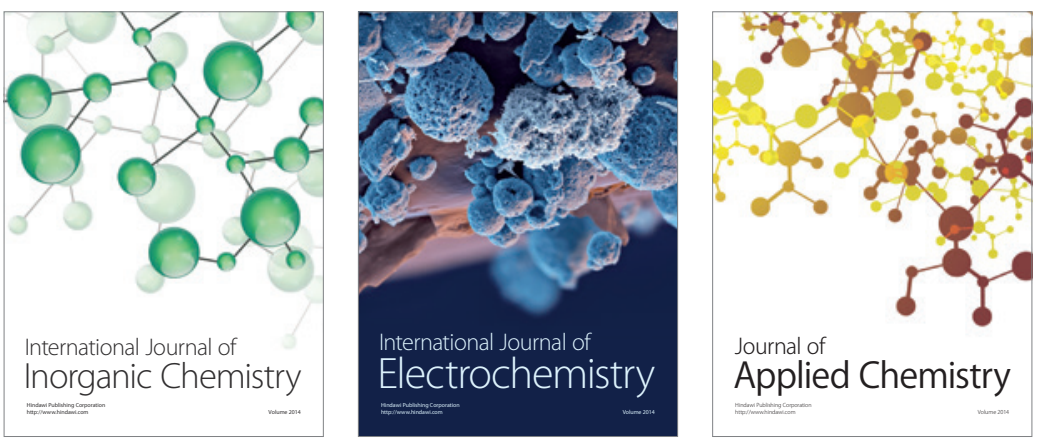

Journal of

Applied Chemistry
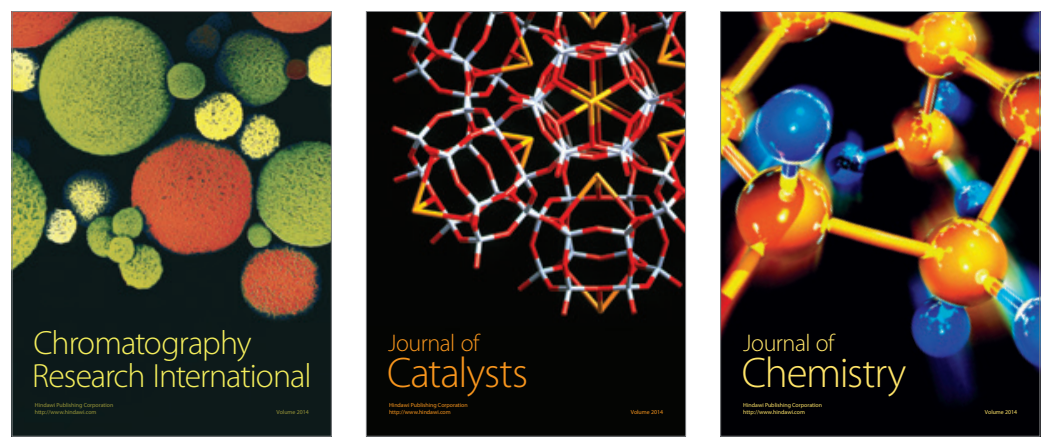
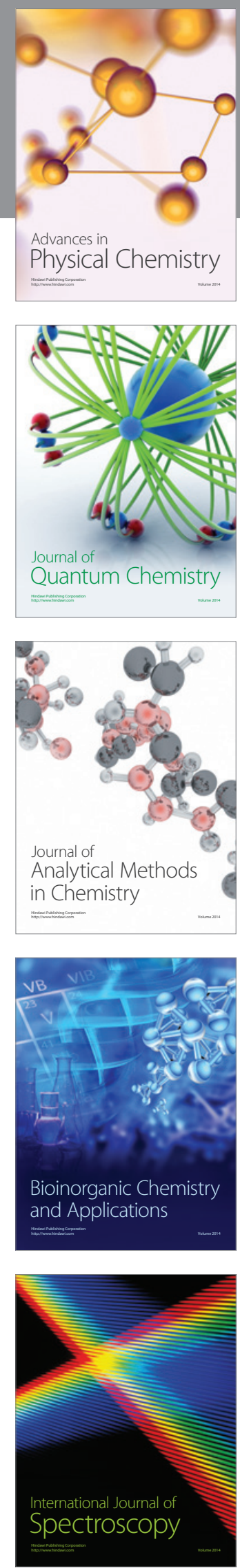